\title{
Article \\ Characterization of Superplastic Deformation Behavior for a Novel Al-Mg-Fe-Ni-Zr-Sc Alloy: Arrhenius-Based Modeling and Artificial Neural Network Approach
}

\author{
Ahmed O. Mosleh ${ }^{1,2}{ }^{(D}$, Anton D. Kotov ${ }^{1}\left(\mathbb{D}\right.$, Anna A. Kishchik ${ }^{1}$, Oleg V. Rofman ${ }^{3}$ and Anastasia \\ V. Mikhaylovskaya ${ }^{1, *}$ \\ 1 Department of Physical Metallurgy of Non-Ferrous Metals, \\ National University of Science and Technology "MISiS", Leninsky Prospekt, 4, 119049 Moscow, Russia; \\ ahmed.omar@feng.bu.edu.eg (A.O.M.); kotov@misis.ru (A.D.K.); kishchik.aa@misis.ru (A.A.K.) \\ 2 Department of Mechanical Engineering, Shoubra Faculty of Engineering, Benha University, Shoubra St. 108, \\ Shoubra, P.O. 11629 Cairo, Egypt \\ 3 Laboratory of Radiation Materials Science, Institute of Nuclear Physics, Ibragimov St. 1, Almaty 050032, \\ Kazakhstan; o.rofman@mail.ru \\ * Correspondence: mihaylovskaya@misis.ru; Tel.: +7-495-638-44-80
}

Citation: Mosleh, A.O.; Kotov, A.D.; Kishchik, A.A.; Rofman, O.V.; Mikhaylovskaya, A.V. Characterization of Superplastic Deformation Behavior for a Novel Al-Mg-Fe-Ni-Zr-Sc Alloy: Arrhenius-Based Modeling and Artificial Neural Network Approach. Appl. Sci. 2021, 11, 2208. https://doi.org/10.3390/ app11052208

Academic Editor: Francisco Alguacil

Received: 8 February 2021

Accepted: 23 February 2021

Published: 3 March 2021

Publisher's Note: MDPI stays neutral with regard to jurisdictional claims in published maps and institutional affiliations.

Copyright: (c) 2021 by the authors. Licensee MDPI, Basel, Switzerland. This article is an open access article distributed under the terms and conditions of the Creative Commons Attribution (CC BY) license (https:/ / creativecommons.org/licenses/by/ $4.0 /)$.

\begin{abstract}
The application of superplastic forming for complex components manufacturing is attractive for automotive and aircraft industries and has been of great interest in recent years. The current analytical modeling theories are far from perfect in this area, and the results deduced from it characterize the forming conditions insufficiently well; therefore, successful numerical modeling is essential. In this study, the superplastic behavior of the novel Al-Mg-Fe-Ni-Zr-Sc alloy with highstrain-rate superplasticity was modeled. An Arrhenius-type constitutive hyperbolic-sine equation model (ACE) and an artificial neural network (ANN) were developed. A comparative study between the constructed models was performed based on statistical errors. A cross validation approach was utilized to evaluate the predictability of the developed models. The results revealed that the ACE and ANN models demonstrated strong workability in predicting the investigated alloy's flow stress, whereas the ACE approach exhibited better predictability than the ANN.
\end{abstract}

Keywords: aluminum alloys; superplasticity; constitutive equations; artificial neural network; crossvalidation

\section{Introduction}

The possibility of producing the weldless complex-shape constructions, which would be difficult or even impossible to produce by other ways, is the main benefit of the superplastic-forming technology (SPF) [1-6]. Xing et al. [7] noted that the curved parts and complex shapes in automotive and aerospace sectors, small-scale structural, and architectural design elements could be fabricated from aluminum alloys, where high stiffness and low weight are desired. Among the different types of aluminum alloys, Al-Mg-based alloys are attractive for transferring into the industry owing to their lower density, good mechanical properties, and high corrosion resistance [8]. The Al-Mg-based AA5083-type alloys are widely used for SPF [9-14]. The main disadvantage of this alloy is a low forming rate of about $10^{-3} \mathrm{~s}^{-1}$, which limits SPF productivity [9-11,15]. Kishchik et al. [16] improved the Al-Mg-based alloy's superplasticity by adding Fe, $\mathrm{Ni}$ (about of $2 \mathrm{wt} \%$ total), and a small amount of Sc and $\operatorname{Zr}(0.3 \mathrm{wt}$.\% total) to the base alloy. Iron and nickel lead to form the coarse particles of the $\mathrm{Al}{ }_{9} \mathrm{FeNi}$ phase [16-23]. Such coarse particles provide the particle-stimulated nucleation (PSN) effect during recrystallization [24-28]. The alloying with complex addition of $\mathrm{Zr}$ and Sc provides high-dense distributed nanoscale precipitates (dispersoids) of the $\mathrm{L1}_{2}$-structured $\mathrm{Al}_{3}(\mathrm{Sc}, \mathrm{Zr}$ ) phase that has a strong Zener pinning effect $[26,29-34]$. Due to lower cost of $\mathrm{Zr}$ and improvement of the coarsening 
resistance of $\mathrm{L}_{2}$ precipitates, partial replacement of $\mathrm{Sc}$ by $\mathrm{Zr}$ is an effective way to provide a fine-grained structure at elevated temperatures [35-41]. As a result, bimodal particle-size distribution with coarse and fine particles helps to provide a fine-grained structure with a limited effect of the dynamic grain growth, leading to excellent superplasticity at the strain rates up to $1 \times 10^{-1} \mathrm{~s}^{-1}[16,42,43]$. It should be noted that a high-strain-rate superplasticity is provided by a simple thermomechanical treatment including homogenization annealing, hot and cold rolling with low reduction.

The material's deformation behavior has a significant effect on the quality of hotworked products $[44,45]$. In general, the superplastic flow stress depends on the temperature, strain rate, and strain. Depending on the alloy structure, strain hardening or strain softening accompanied the deformation. Thus, an appropriate constitutive model, which correlates with these factors, is required to designate the SPF parameters and predict the flow stress. Superplastic deformation modeling has been of great interest over the years, and many computational algorithms have been proposed for aluminum alloys [46-56]. Among these computational algorithms, constitutive equations and artificial neural networks (ANN) are widely used to model the superplastic flow behavior. Li et al. [56] examined the deformation behavior of the AA7050 Al-Zn-Mg-based alloy, which demonstrated strain hardening and developed a constitutive equation considering the strain compensation. The accuracy of the developed model for the AA7050 alloy was verified by comparing the experimental and predicted findings. Chen et al. [44] modeled the hot deformation behavior of the AA7005 alloy. The comparisons between the experimental and the predicted data prove the quality of the constructed Arrhenius-type model. Yakovtseva et al. [55] developed an artificial neural network (ANN) and Arrhenius-type constitutive models (ACE) to predict the flow behavior accompanied with strain softening for the Al-Zn-Mg-based alloy. The cross-validation technique demonstrated a good precision for both constructed models [55]. This study aims to develop a mathematical model for predicting the superplastic flow behavior of the novel Al-Mg-Fe-Ni-based alloy, demonstrating high-strain-rate superplasticity and strain softening during the deformation. For this purpose, the ACE and ANN approaches were involved, and their accuracies were compared.

\section{Materials and Methods}

The Al-4.9Mg-0.9Fe-0.9Ni-0.2Zr-0.1Sc (wt.\%) alloy was investigated. The alloy was processed in a laboratory. The $99.85 \% \mathrm{Al}, 99.5 \% \mathrm{Mg}$, and the master alloys of $\mathrm{Al}-10 \% \mathrm{Fe}$, $\mathrm{Al}-10 \% \mathrm{Ni}, \mathrm{Al}-2 \% \mathrm{Sc}$, and Al-5\% Zr were used for the alloy preparation. A Nabertherm K4/13 electric furnace (Nabertherm $\mathrm{GmbH}$, Lilienthal, Germany) with air atmosphere was used for melting. The casting was processed at a temperature of $780 \pm 10^{\circ} \mathrm{C}$. The ingot with a size of $30 \times 120 \times 250 \mathrm{~mm}$ was cast using a semicontinuous method in a water-cooled system providing a casting-cooling rate of about $5 \mathrm{~K} / \mathrm{s}$. The sheet was processed using the following stages: (1) homogenization annealing at $350{ }^{\circ} \mathrm{C}$ for $8 \mathrm{~h}$ and $450{ }^{\circ} \mathrm{C}$ for $2 \mathrm{~h}$, (2) hot rolling at a temperature of $400 \pm 10{ }^{\circ} \mathrm{C}$ for the reduction of $70 \%$, and (3) cold rolling at room temperature for the reduction of $50 \%$. The heat treatment was performed in a Nabertherm N60/85HA furnace (Nabertherm GmbH, Lilienthal, Germany) with air-force convection.

The microstructure was examined with scanning electron microscopy (SEM) using a Tescan-VEGA3 (Tescan Brno s.r.o., Kohoutovice, Czech Republic) equipped with an X-MAX80 (Oxford Instruments plc, Abingdon, UK) energy dispersive spectrometry (EDS) system. The samples were prepared by mechanical grinding using SiC papers and polishing in a $20 \%$ water solution of colloidal silica-based suspension. An Axiovert 200 MMAT (Carl Zeiss, Oberkochen, Germany) light microscopy (LM) with polarized light was used to analyze the grain structure. The samples were subjected to anodizing at a voltage of $20 \mathrm{~V}$ for $20 \mathrm{~s}$ in a $10 \%$ water solution of the $\mathrm{H}_{3} \mathrm{BO}_{4}$ saturated in the $\mathrm{HF}$.

A JEOL JEM 2100 (JEOL, Japan) transmission electron microscope (TEM) was used to study the dislocation structure and fine precipitates' parameters. The operating voltage was $200 \mathrm{kV}$. The TEM samples of $3 \mathrm{~mm}$ in diameter were cut from a plate of $0.25 \mathrm{~mm}$ thickness. 
The electrochemical thinning of the samples was performed in a Struers TenuPol-5 (Struers APS, Ballerup, Denmark) at a voltage of $22 \pm 1 \mathrm{~V}$ using an A2 electrolyte (Struers APS, Ballerup, Denmark) at a temperature of $0 \pm 2{ }^{\circ} \mathrm{C}$.

Isothermal uniaxial tensile tests via a Walter + Bay LFM100 test machine (Walter + Bai AG, Löhningen, Switzerland) were used to characterize the investigated alloy's superplastic flow behavior. The tests were performed at a temperature of $420,460,500$, and $540{ }^{\circ} \mathrm{C}$ and a strain rate range of $0.002-0.1 \mathrm{~s}^{-1}$. The flow behavior data were used to construct $\mathrm{ACE}$ and ANN models. In the ACE model, the model parameters were correlated with strain for accurate prediction. Three layers of the backpropagation network were involved, i.e., the input layer (strain, strain rate, and temperature), the output layer (flow stress), and the hidden layer. The predictability of the constructed models is quantified by the correlation coefficient (R) (Equation (1)), the average absolute relative error (AARE) (Equation (2)), and the root mean square error (RMSE) (Equation (3)):

$$
\begin{gathered}
R=\frac{\sum_{i=1}^{N}\left(E_{i}-\bar{E}\right)\left(P_{i}-\bar{P}\right)}{\sqrt{\sum_{i=1}^{N}\left(E_{i}-\bar{E}\right)^{2} \sum_{i=1}^{N}\left(P_{i}-\bar{P}\right)^{2}}} \\
\operatorname{AARE}(\%)=\frac{1}{N} \sum_{i=1}^{N}\left|\frac{E_{i}-P_{i}}{E_{i}}\right| \\
R M S E=\sqrt{\frac{1}{N} \sum_{i=1}^{N}\left(E_{i}-P_{i}\right)^{2}}
\end{gathered}
$$

where;

- $\quad E_{i}$, and $P_{i}$ are the experimental and modeled flow stress,

- $\quad \bar{E}$ and $\bar{P}$ are the mean values of the experimental and modeled flow stress, and

- $\quad N$ is the sample size.

\section{Results and Discussion}

\subsection{Microstructural Parameters of the Alloy Studied}

The alloy studied contained the aluminum-based solid solution as a matrix phase and the secondary particles of the Fe- and Ni-enriched phase (Figure 1a,b), a small fraction of the $\mathrm{Mg}_{2} \mathrm{Si}$ phase owing to the residual Si and the $\mathrm{L1}_{2}$-strucutred phase (Figure $1 \mathrm{c}, \mathrm{d}$ ). The coarse $\mathrm{Ni}$ - and Fe-bearing particles belonged to the $\mathrm{Al}_{9} \mathrm{FeNi}$ phase of crystallization (eutectic) origin $[20,57,58]$. A mean size of the coarse particles was $0.8 \pm 0.1 \mu \mathrm{m}$, and their volume fraction was $8 \pm 1 \%$. The $\mathrm{L1}_{2}$-structured dispersoids belonged to the $\mathrm{Al}_{3}(\mathrm{Sc}, \mathrm{Zr})$ phase which precipitated during thermomechanical treatment [59-61]. The $\mathrm{L}_{2}$ precipitates demonstrated the superlattice reflexes in SAED and the Ashby-Brown contrast owing to the precipitates coherency with the Al matrix (Figure 1c) $[59,62,63]$. The mean size of the $\mathrm{L}_{2}$ precipitates was $11 \pm 1 \mathrm{~nm}$. Fine and coarse precipitates were near-uniformly distributed in the aluminum matrix. Due to the nanoscale dispersoids, the sheets demonstrated a predominantly non-recrystallized grain structure before the start of the superplastic deformation in a temperature range of $420-540{ }^{\circ} \mathrm{C}$ (Figure 2). The TEM study confirmed the formation of subgrains after annealing of the samples at $500{ }^{\circ} \mathrm{C}$ (Figure $\left.1 \mathrm{c}, \mathrm{d}\right)$. 

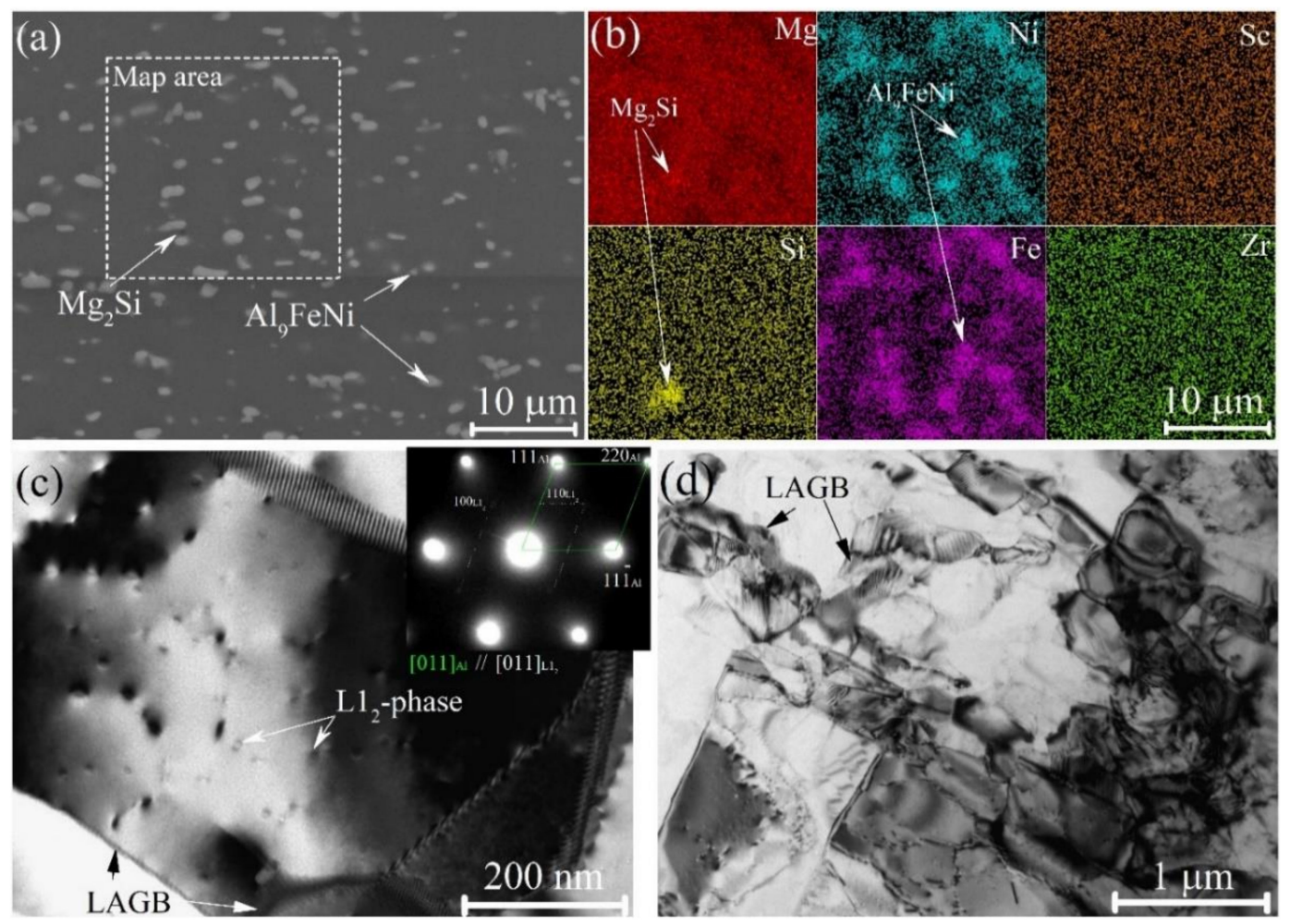

Figure 1. Microstructures for the Al-Mg-Fe-Ni-Zr-Sc alloy studied before the start of the superplastic deformation at $500{ }^{\circ} \mathrm{C}$; (a) SEM image (b) SEM-EDS element distribution maps for the alloying elements (c,d) TEM images; insert: SAED for (c) image.

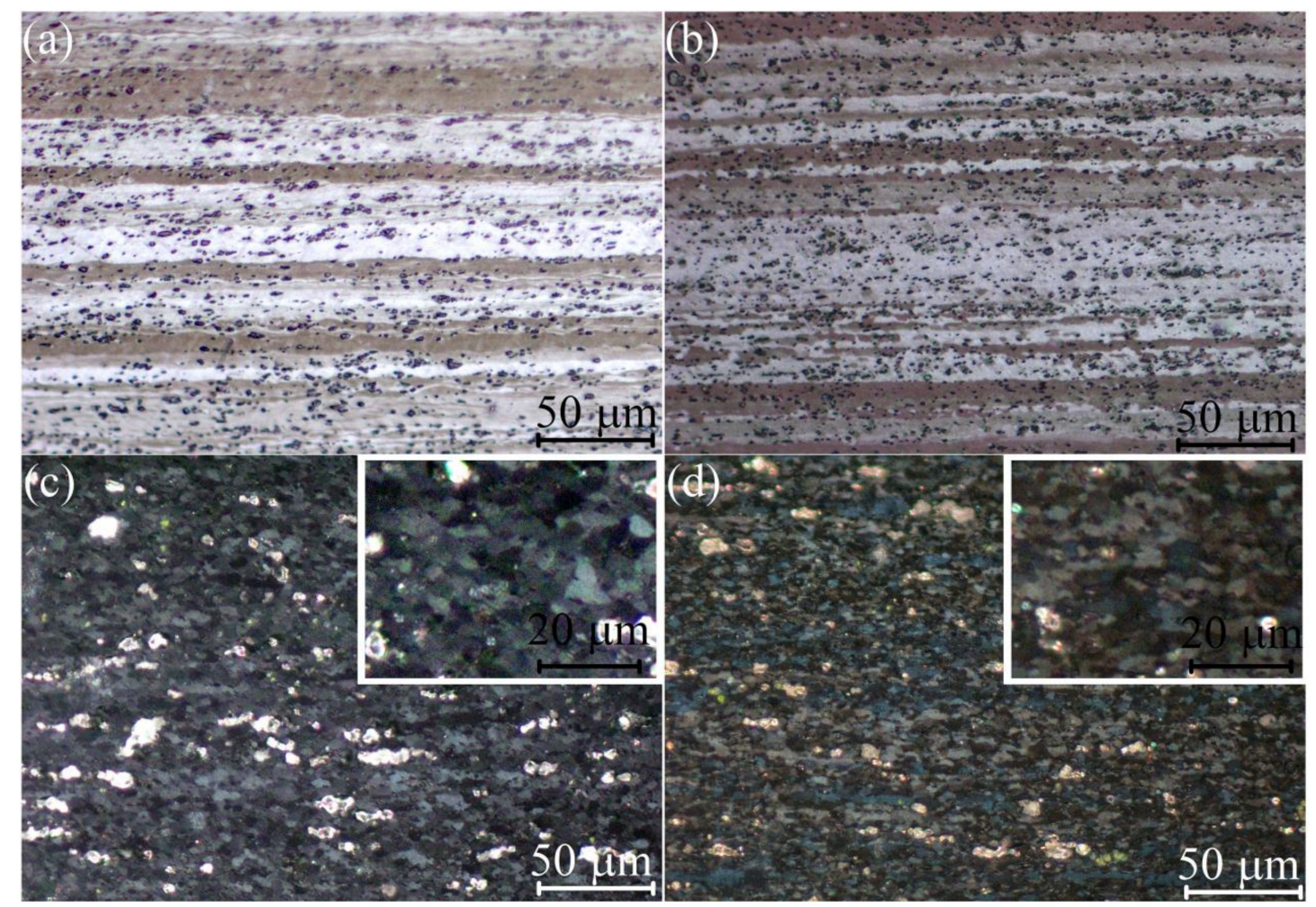

Figure 2. Grain structure of the investigated Al-Mg-Fe-Ni-Zr-Sc alloy $(\mathbf{a}, \mathbf{b})$ before the start of the superplastic deformation at (a) $420^{\circ} \mathrm{C}$, (b) $540{ }^{\circ} \mathrm{C}$, and (c,d) after the superplastic deformation (logarithmic strain of 1.5) at a temperature of $460{ }^{\circ} \mathrm{C}$ with strain rates of (c) 0.008 and (d) $0.06 \mathrm{~s}^{-1}$. 
The recrystallized grains were formed during the superplastic deformation. The grain structures after the strain of 1.5 at a temperature of $460{ }^{\circ} \mathrm{C}$ with strain rates of 0.008 and $0.06 \mathrm{~s}^{-1}$ are presented in Figure 2c,d. The mean grain size of $4.6 \pm 0.5$ and $3.5 \pm 0.4 \mu \mathrm{m}$ at 0.008 and $0.06 \mathrm{~s}^{-1}$ was formed respectively; therefore, a higher strain rate of superplastic deformation provided a finer grain structure.

\subsection{Tensile Test Results}

The elongation-to-failure exceeded $250 \%$ in the studied temperatures and constant strain rates of $460-500{ }^{\circ} \mathrm{C}$ and of $10^{-3}-10^{-2} \mathrm{~s}^{-1}$ (Figure 3a). The elongation above $500 \%$ was observed at the studied temperatures for a strain rate of about $1 \times 10^{-2} \mathrm{~s}^{-1}$ with a maximum mean elongation value of $560 \pm 30 \%$ at $460{ }^{\circ} \mathrm{C}$ and $0.8 \times 10^{-2} \mathrm{~s}^{-1}$ and $540{ }^{\circ} \mathrm{C}$ and $2 \times 10^{-3} \mathrm{~s}^{-1}$. The strain-rate-sensitivity $\mathrm{m}$-values calculated for a strain of $200 \%$ for each testing conditions are presented in Figure 3b. The temperature-strain-rate conditions provided the maximum $m$-value were corresponded with the testing regimes for the maximum elongations.

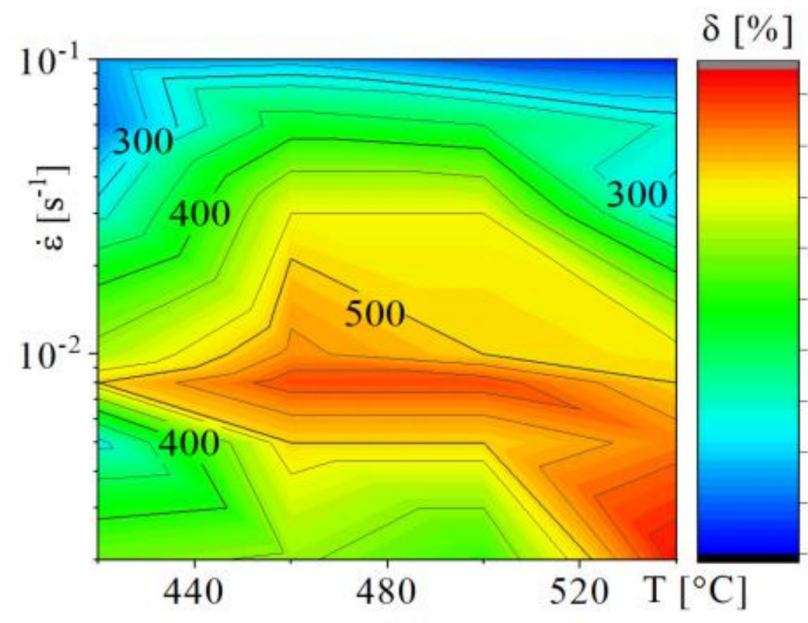

(a)

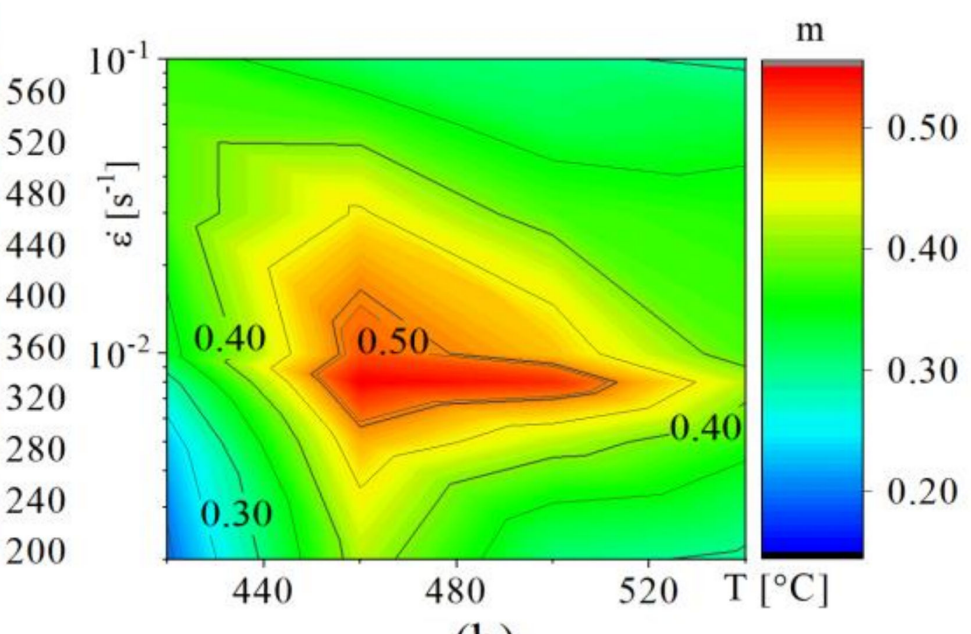

(b)

Figure 3. (a) Elongation to failure and (b) the strain-rate-sensitivity $m$ coefficient as a function of temperature and a constant strain rate of the investigated Al-Mg-Fe-Ni-Zr-Sc alloy.

The superplastic behavior is characterized by elongations above $200 \%$ and $m$-values above 0.3 [64-66]. The experimental stress-strain data for strains below 200\% (Figure 4) were used to develop mathematical models of the superplastic flow for the testing conditions providing required high elongation and $m$. An increase in the deformation temperature or a decrease in the strain rate expectedly decreased the peak stress values. Strain softening, attributed to dynamic recrystallization, was observed for most of the testing conditions that in agreement with [16]. 

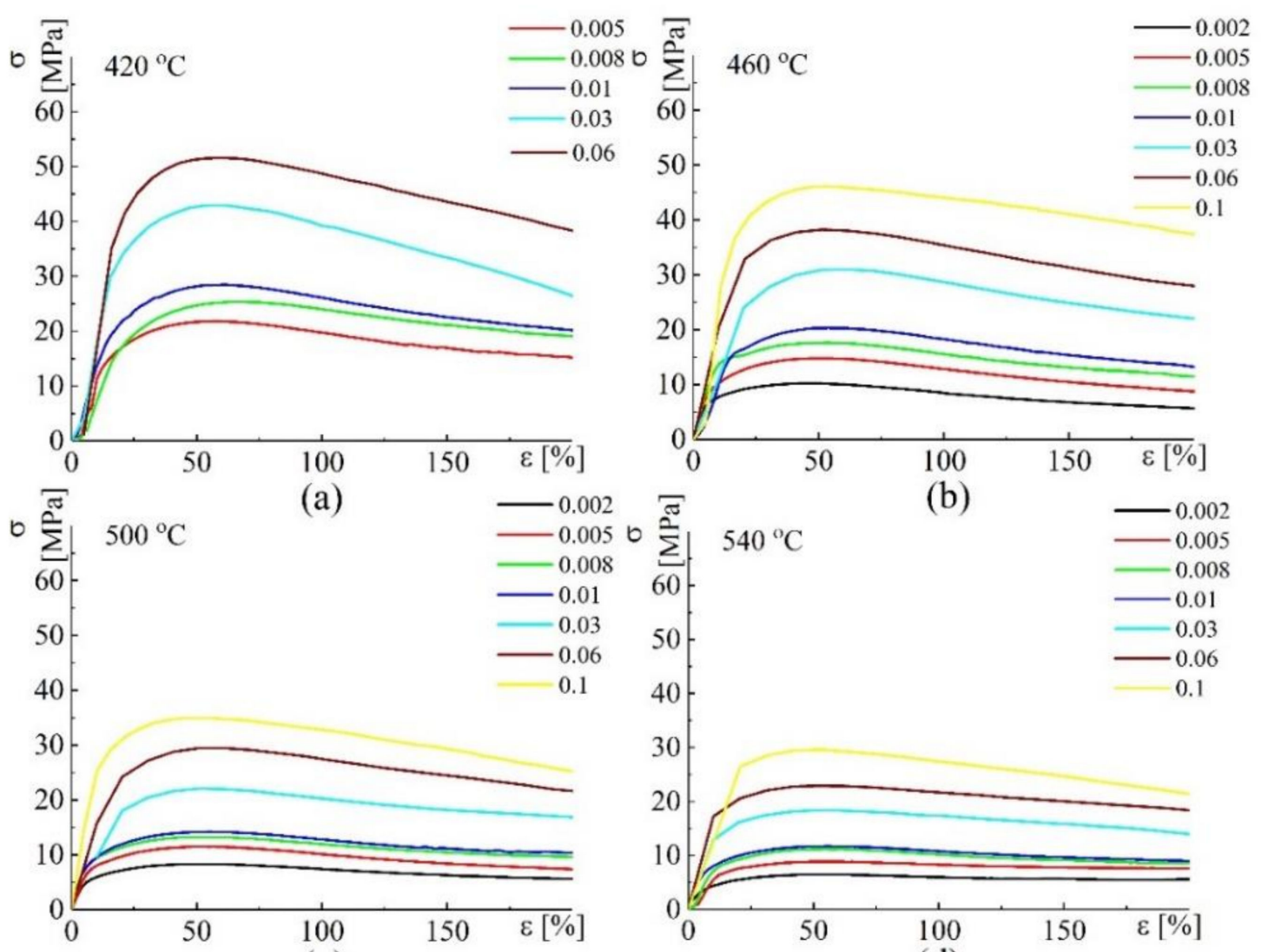

(c)

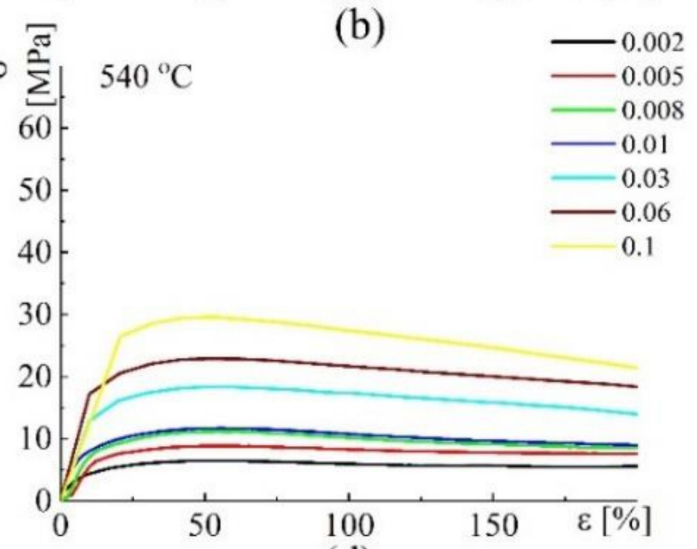

(d)

Figure 4. Experimental flow behavior at temperatures of (a) $420^{\circ} \mathrm{C}$, (b) $460{ }^{\circ} \mathrm{C}$, (c) $500{ }^{\circ} \mathrm{C}$, and (d) $540{ }^{\circ} \mathrm{C}$ with various constant strain rates.

\subsection{Flow Stress Behavior Modeling Experiments}

In this work, the Arrhenius-type constitutive hyperbolic equation (ACE) and artificial neural network (ANN) were created to predict the flow behavior of the investigated alloy. The experimental data obtained from the uniaxial isothermal tensile tests were utilized to construct these models. Over this section, the sequences of each model's creation and the validation process are described in detail.

\subsubsection{ACE Model}

As follows (Equation (4)), the flow stress $(\sigma)$ varies with the deformation temperature $(T)$, strain rate $(\dot{\varepsilon})$, and strain $(\varepsilon)$.

$$
\sigma=f(T, \dot{\varepsilon}, \varepsilon)
$$

In an exponent-type equation, the Zener-Holloman parameter $(Z)$ was used to identify the relationship between $T, \dot{\varepsilon}$ and $\varepsilon$ (Equations (5) and (6)) $[67,68]$. The equation constants are collected in Table 1.

$$
\dot{\varepsilon}=A f(\sigma)\left(\exp ^{\left(-\frac{Q}{R T}\right)}\right)=\left\{\begin{array}{c}
Z=\dot{\varepsilon}\left(\exp ^{\left(\frac{Q}{R T}\right)}\right) \\
A_{1} \sigma^{n_{1}}\left(\exp ^{\left(-\frac{Q 1}{R T}\right)}\right)-\text { Power law } \\
A_{2}(\exp (\beta \sigma))\left(\exp ^{\left(-\frac{Q 2}{R T}\right)}\right)-\text { Exponential law } \\
A_{3}[\sinh (\alpha \sigma)]^{n_{2}}\left(\exp ^{\left(-\frac{Q 3}{R T}\right)}\right)-\text { Hyperbolic sine law }
\end{array}\right.
$$


Table 1. The equations constants.

\begin{tabular}{cl}
\hline $\mathrm{A}_{1,2,3}, \alpha\left(\alpha=\beta / n_{1}\right), \beta, n_{1}, n_{2}$ & the material constants that vary with the strain \\
\hline $\mathrm{Q}_{1,2,3}$ & the activation energy of the deformation, $\mathrm{J} / \mathrm{mol}$ \\
\hline $\mathrm{T}$ & the absolute temperature, $\mathrm{K}$ \\
$\mathrm{R}$ & the universal gas constant, $8.314 \mathrm{~J} /(\mathrm{mol} . \mathrm{K})$ \\
\hline
\end{tabular}

In general, due to its high efficiency in large ranges of stress levels, the hyperbolic sine law was used to create the proposed constitutive model [69].

\section{Constants Determination}

An example was taken to implement the solution procedures to determine the equation constants at a strain of $50 \%$. By taking the logarithm of both sides of Equation (6), the following Equations (7)-(9) were expressed.

$$
\begin{gathered}
\ln \dot{\varepsilon}=\ln A_{1}+n_{1} \ln \sigma-\frac{Q_{1}}{R T} \\
\ln \dot{\varepsilon}=\ln A_{2}+\beta \sigma-\frac{Q_{2}}{R T} \Rightarrow \\
\ln \dot{\varepsilon}=\ln A_{3}+n_{2} \ln \sinh (\alpha \sigma)-\frac{Q_{3}}{R T}
\end{gathered}
$$

By partial differentiation of Equations (7)-(9) and Equations (7)-(15) were derived.

$$
\begin{gathered}
n_{1}=\left[\frac{\partial \ln \dot{\varepsilon}}{\partial \ln \sigma}\right]_{T} \\
\beta=\left[\frac{\partial \ln \dot{\varepsilon}}{\partial \sigma}\right]_{T} \\
n_{2}=\left[\frac{\partial \ln \dot{\varepsilon}}{\partial \ln [\sinh (\alpha \sigma)]}\right]_{T} \\
Q_{1}=R \times\left[\frac{\partial \ln \dot{\varepsilon}}{\partial \ln \sigma}\right]_{T} \times\left[\frac{\partial \ln \sigma}{\left.\partial\left(\frac{1}{T}\right)\right]_{\dot{\varepsilon}}}\right. \\
Q_{2}=R \times\left[\frac{\partial \ln \dot{\varepsilon}}{\partial \sigma}\right]_{T} \times\left[\frac{\partial \sigma}{\left.\partial\left(\frac{1}{T}\right)\right]_{\dot{\varepsilon}}}\right. \\
Q_{3}=R \times\left[\frac{\partial \ln \dot{\varepsilon}}{\partial \ln [\sinh (\alpha \sigma)]}\right]_{T} \times\left[\frac{\partial \ln [\sinh (\alpha \sigma)]}{\partial\left(\frac{1}{T}\right)}\right]_{\dot{\varepsilon}}
\end{gathered}
$$

Figure 5 illustrates the $\ln \dot{\varepsilon}-\ln \sigma$ (Figure 5a), $\ln \dot{\varepsilon}-\sigma$ (Figure 5b), $\ln \dot{\varepsilon}-\ln \sinh (\alpha \sigma)$ (Figure $5 c$ ), and $\ln \sinh (\alpha \sigma)-\frac{1000}{R T}$ (Figure $5 d$ ) linear plots. The $n_{1}, \beta$, and $Q_{1,2}$ constants were computed as the correlation coefficients of the slopes of the $\ln \dot{\varepsilon}-\ln \sigma$ and $\ln \dot{\varepsilon}-\sigma$ plots, respectively (Figure 5a,b). While $n_{2}$ and $Q_{3}$ were obtained from the slope of the plots of $\ln \dot{\varepsilon}-\ln \sinh (\alpha \sigma)$ and $\ln \sinh (\alpha \sigma)-\frac{1000}{R T}$ (Figure $5 \mathrm{c}, \mathrm{d}$ ). The equations constants at a strain of $50 \%$ for the investigated alloy are collected in Table 2 . 


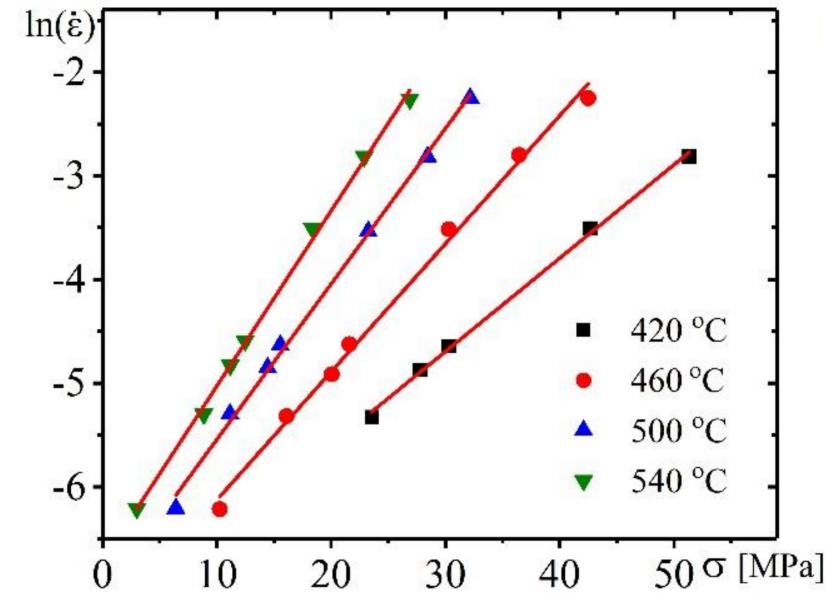

(a)

$\ln (\ddot{\varepsilon})$

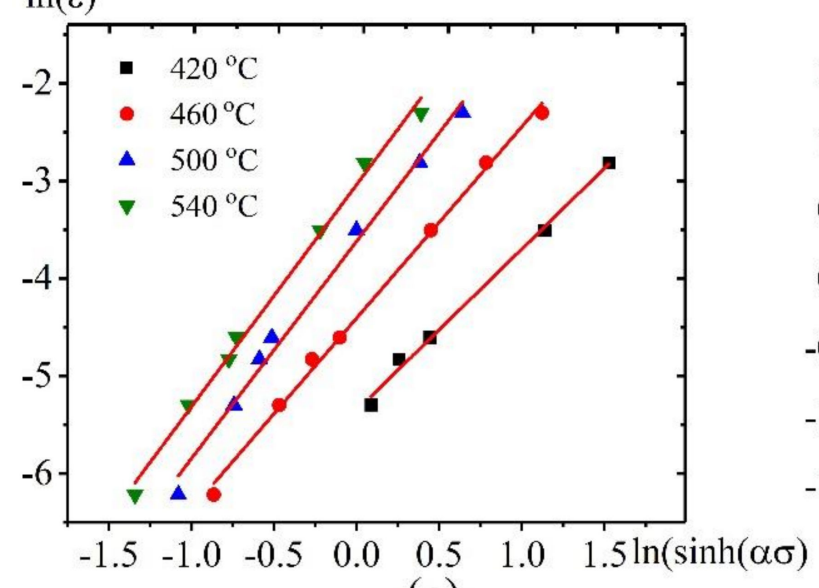

(c)

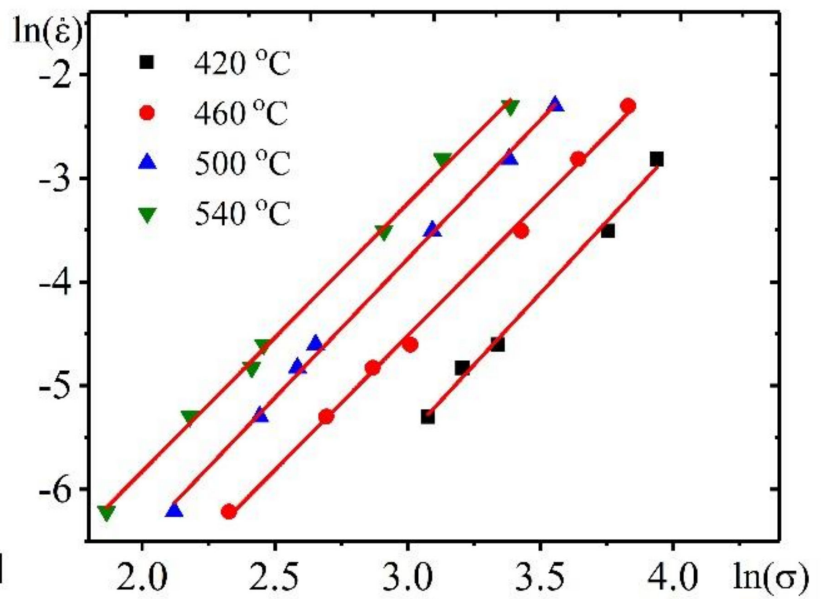

(b)

$\ln (\sinh (\alpha \sigma)$

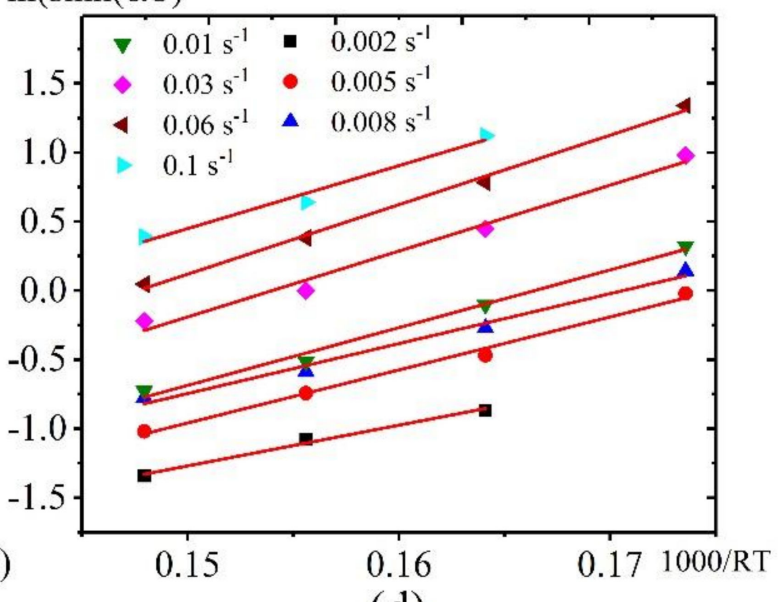

(d)

Figure 5. Plots of (a) $\ln \dot{\varepsilon}-\ln \sigma$, (b) $\ln \dot{\varepsilon}-\sigma$, (c) $\ln \dot{\varepsilon}-\ln \sinh (\alpha \sigma)$, and (d) $\ln \sinh (\alpha \sigma)-\frac{1000}{R T}$ corresponding to a strain of $50 \%$.

Table 2. The determined constants of the Arrhenius-type constitutive hyperbolic-sine equation model (ACE) at a strain of $50 \%$ of the investigated alloy.

\begin{tabular}{cccccccccc}
\hline $\ln \left(\mathbf{A}_{\mathbf{1}}\right)$ & $\mathbf{n}_{\mathbf{1}} / \mathbf{m} *$ & $\begin{array}{c}\mathbf{Q}_{\mathbf{1}} \\
{[\mathrm{KJ} / \mathbf{m o l}]}\end{array}$ & $\ln \left(\mathbf{A}_{\mathbf{2}}\right)$ & $\begin{array}{c}\beta \\
{\left[\mathbf{M P a}^{-1}\right]}\end{array}$ & $\begin{array}{c}\mathbf{Q}_{2} \\
{[\mathbf{k J} / \mathbf{m o l}]}\end{array}$ & $\alpha$ & $\ln \left(\mathbf{A}_{3}\right)$ & $\mathbf{n}_{\mathbf{2}}$ & $\begin{array}{c}\mathbf{Q}_{3} \\
{[\mathbf{k J} / \mathbf{m o l}]}\end{array}$ \\
\hline 1.6 & $2.6 / 0.4$ & $86 \pm 5$ & 6.1 & 0.11 & $80 \pm 5$ & 0.04 & 9.4 & 1.99 & $86 \pm 5$ \\
\hline
\end{tabular}

* The strain-rate sensitivity $(\mathrm{m})$ was calculated by $m=\frac{1}{n_{1}}$.

The strain rate and the flow stress at a strain of 50\% dependent on the hyperbolic sine law can be calculated as follows (Equations (16) and (17)) once the ACE constants were determined:

$$
\dot{\varepsilon}=A_{3}[\sinh (\alpha \sigma)]^{n_{2}} \exp ^{\left(-\frac{Q}{R T}\right)}=12160[\sinh (0.04 \sigma)]^{1.99} \exp ^{\left(-\frac{86 \times 1000}{R T}\right)}
$$

$$
\sigma=\frac{1}{\alpha} \ln \left\{\left(\frac{z}{A_{3}}\right)^{\frac{1}{n_{2}}}+\left[\left(\frac{z}{A_{3}}\right)^{\frac{2}{n_{2}}}+1\right]^{\frac{1}{2}}\right\}=\frac{1}{0.04} \ln \left\{\left(\frac{\dot{\varepsilon} \exp ^{\frac{86 \times 10^{3}}{R T}}}{12160}\right)^{\frac{1}{1.99}}+\left[\left(\frac{\dot{\varepsilon} \exp p^{\frac{86 \times 10^{3}}{R T}}}{12160}\right)^{\frac{2}{1.99}}+1\right]^{\frac{1}{2}}\right\}
$$


To model the flow behavior, the strain impact on the ACE model constants should be regarded. Thus, the ACE model constants $\alpha, Q_{3}, \ln \left(A_{3}\right)$, and $n_{2}$ versus a different strain were computed (Figure 6a-d).

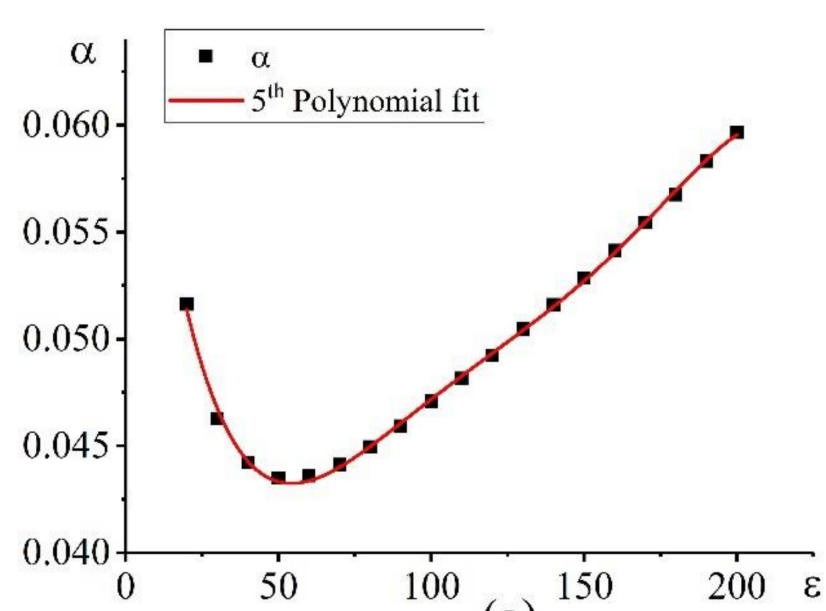

(a)

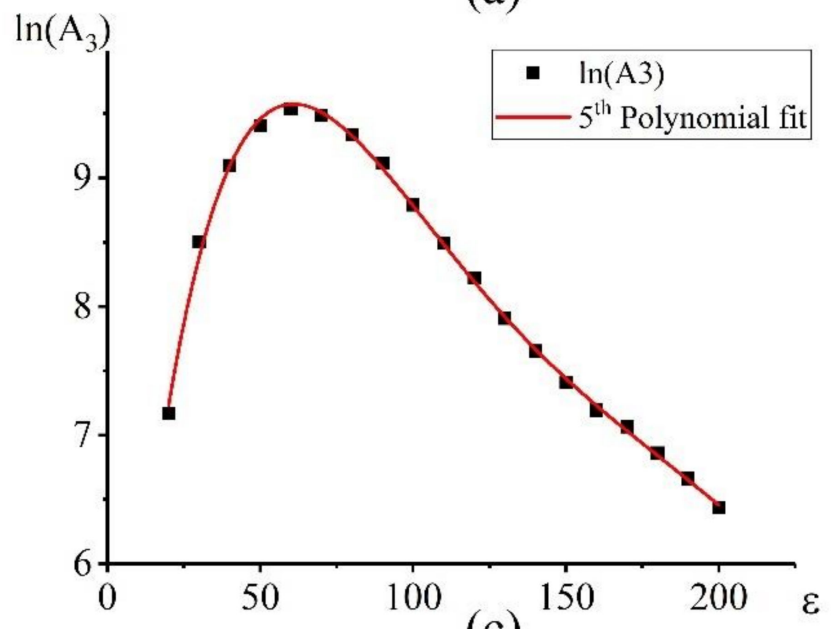

(c)

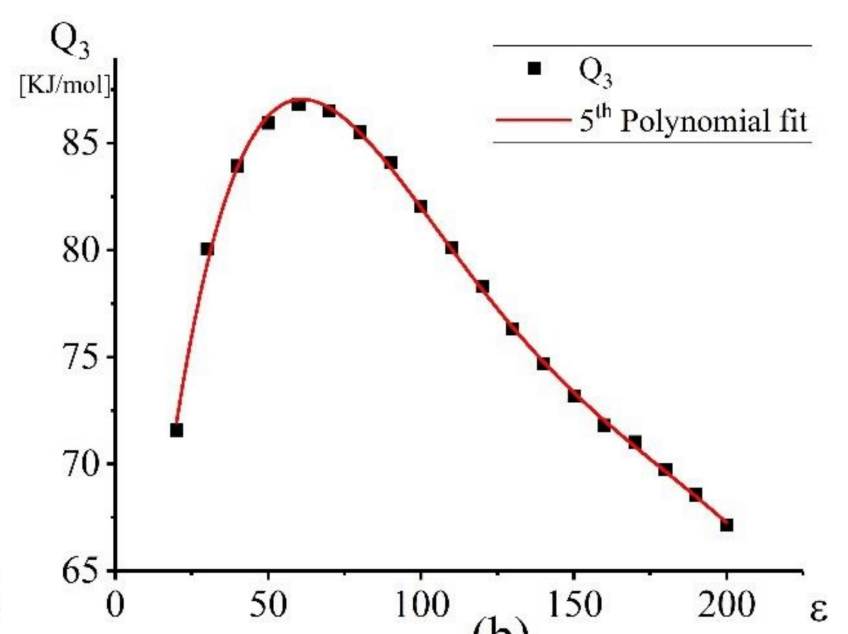

(b)

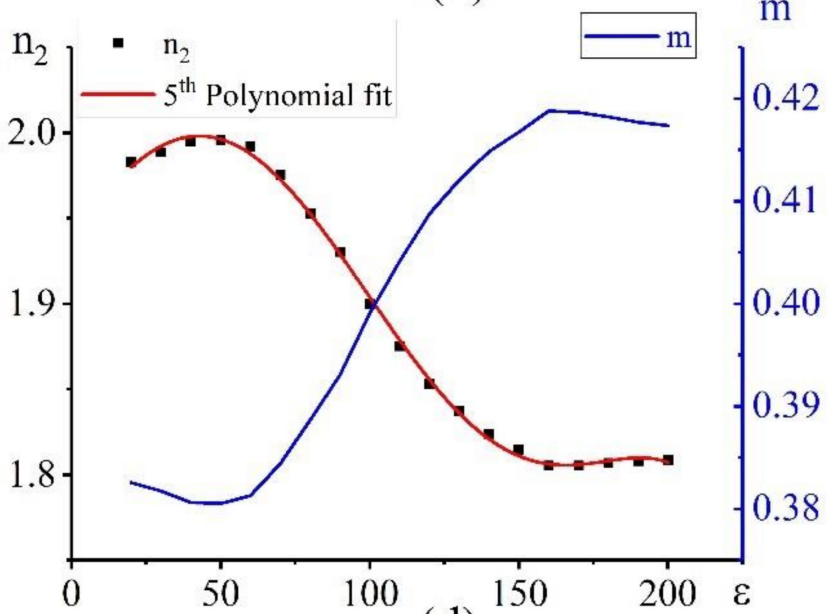

(d)

Figure 6. Dependence of the (a) $\alpha,(\mathbf{b}) Q_{3},(\mathbf{c}) \ln \left(A_{3}\right)$, and (d) $n_{2}$ vs. strain.

The 5th polynomial order was the best relevant order, depending on the determination coefficient $\left(\mathrm{R}^{2}\right)$, for all ACE model constants, the polynomial regression coefficients were as follows (Equations (18)-(21)):

$$
\begin{gathered}
\alpha=a+b(\varepsilon)+c\left(\varepsilon^{2}\right)+d\left(\varepsilon^{3}\right)+e\left(\varepsilon^{4}\right)+\mathrm{f}\left(\varepsilon^{5}\right) \\
Q_{3}=a+b(\varepsilon)+c\left(\varepsilon^{2}\right)+d\left(\varepsilon^{3}\right)+e\left(\varepsilon^{4}\right)+f\left(\varepsilon^{5}\right) \\
\operatorname{Ln}\left(A_{3}\right)=a+b(\varepsilon)+c\left(\varepsilon^{2}\right)+d\left(\varepsilon^{3}\right)+e\left(\varepsilon^{4}\right)+f\left(\varepsilon^{5}\right) \\
\mathrm{n}_{2}=a+b(\varepsilon)+c\left(\varepsilon^{2}\right)+d\left(\varepsilon^{3}\right)+e\left(\varepsilon^{4}\right)+f\left(\varepsilon^{5}\right)
\end{gathered}
$$

where $a, b, c, d, e$, and $f$ are the polynomial regression coefficients, $R^{2}$ is the coefficient of determination, which is shown in Table 3. 
Table 3. The calculated polynomial regression coefficients and $R^{2}$ in Equations (18)-(21).

\begin{tabular}{ccccc}
\hline & $\alpha$ & $Q_{3}$ & $\operatorname{Ln}\left(\boldsymbol{A}_{3}\right)$ & $\boldsymbol{n}_{2}$ \\
\hline $\mathrm{a}$ & 0.07 & 52.5 & 4.33 & 2.69 \\
$\mathrm{~b}$ & -0.001 & 1.62 & 0.26 & $6.91 \times 10^{-4}$ \\
$\mathrm{c}$ & $2.42 \times 10^{-5}$ & -0.02 & -0.004 & $4.30 \times 10^{-5}$ \\
$\mathrm{~d}$ & $-1.99 \times 10^{-7}$ & $1.59 \times 10^{-4}$ & $2.61 \times 10^{-5}$ & $-1.26 \times 10^{-6}$ \\
$\mathrm{e}$ & $7.94 \times 10^{-10}$ & $-4.88 \times 10^{-7}$ & $-8.22 \times 10^{-8}$ & $8.49 \times 10^{-9}$ \\
$\mathrm{f}$ & $-1.22 \times 10^{-12}$ & $5.75 \times 10^{-10}$ & $1.00 \times 10^{-10}$ & $-1.74 \times 10^{-11}$ \\
$\mathrm{R}^{2}$ & 0.997 & 0.999 & 0.998 & 0.997 \\
\hline
\end{tabular}

Once the ACE model's constants were computed through Equations (18)-(21), the flow stress at an effective strain rate was predicted using Equation (17). Figure 7 compares the experimental and the predicted stress vs. strain via the ACE model at different temperatures and strain rates. The ACE modeled stress-strain data well fitted the experimental stressstrain superplastic behavior for the alloy studied.
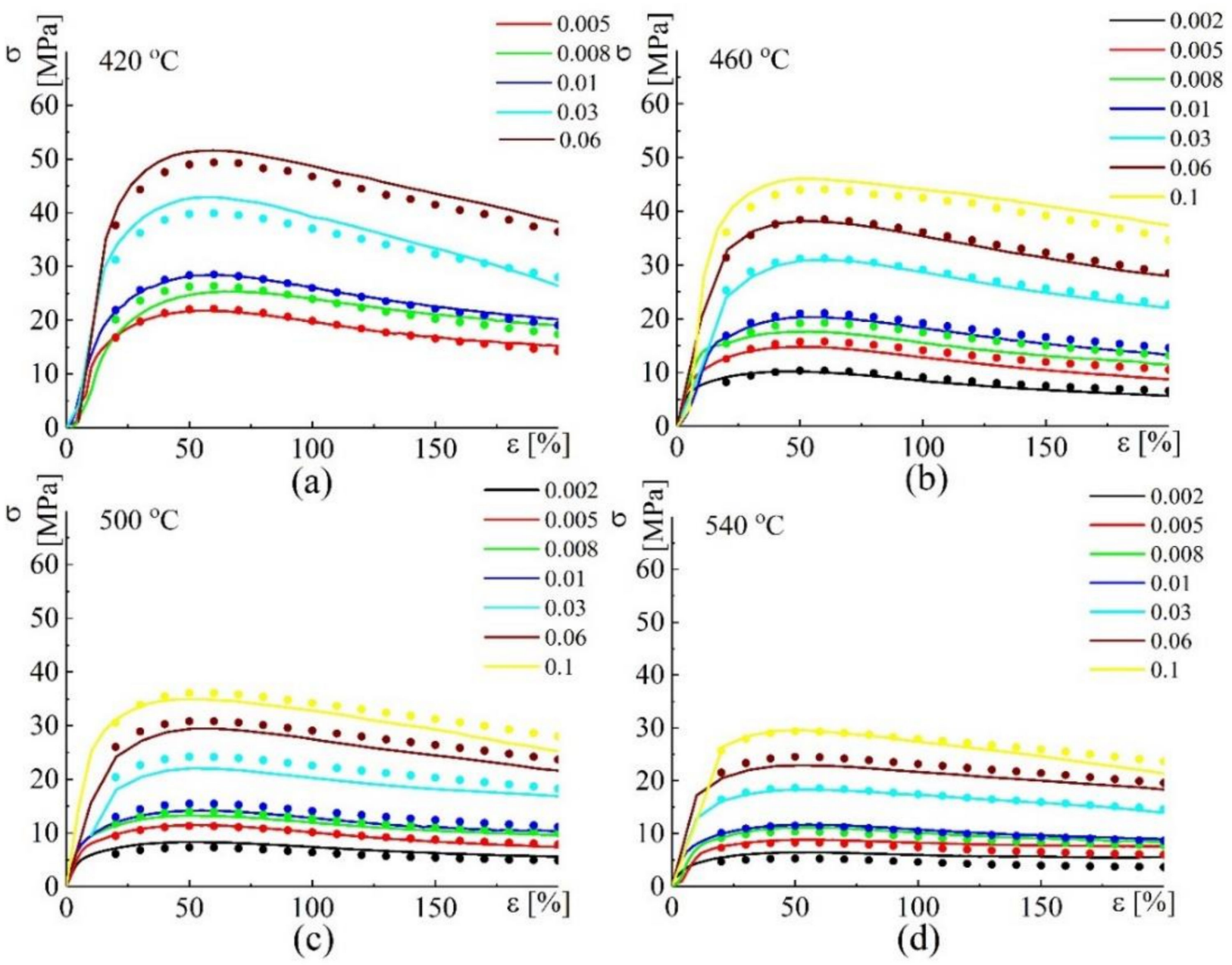

Figure 7. Experimental and predicted stress vs. strain via the ACE model at different strain rates and temperatures of (a) $420^{\circ} \mathrm{C}$, (b) $460^{\circ} \mathrm{C}$, (c) $500^{\circ} \mathrm{C}$, and (d) $540{ }^{\circ} \mathrm{C}$.

The values for the effective (apparent) activation energy of about 75-90 kJ/mol were close to the value of the activation energy of the grain boundary self-diffusion for pure aluminum, $\mathrm{Q}_{\mathrm{GB}}=84-86 \mathrm{~kJ} / \mathrm{mol}[70,71]$. Thus, the effective activation energy values suggested that the superplastic deformation was controlled by the grain boundary diffusion. The same effective activation energy of the superplastic deformation with the activation 
energy for the grain boundary self-diffusion were observed for various superplastic alloys [72-76]. A small increase of the activation energy along with increasing the strain for small strain values may be explained by the increased dislocation activity required for dynamic recrystallization. This suggestion agrees with the grain structure evolution of the alloy studied and the experimental data in [16]. A mean $m$-value for the studied strain-ratetemperature conditions reached 0.41 for $200 \%$ of strain, and, for the temperature of $460{ }^{\circ} \mathrm{C}$ and $1 \times 10^{-2} \mathrm{~s}^{-1}$ providing the maximum elongation, $m$ exceeded 0.5 . These values suggested that the grain boundary sliding mechanism was predominant, and its contribution increased with increasing strain in the studied strain range [16]. The effective (apparent) activation energy slightly decreased, and the $m$-value increased with an increase in strain due to dynamic recrystallization and a related increase in the HAGB fraction [16]. The alloy studied deformation behavior agrees with the data for other dynamically recrystallized $\mathrm{Zr}$ and Sc bearing aluminum-based alloys [23,55,77-79].

\subsubsection{ANN Model}

Due to its simplicity and quick response, the ANN was commonly used to model and simulate metallic materials' flow behavior. Accordingly, the main objective here was to examine the predictability of the investigated alloy's flow behavior via the developed ANN and the classical method based on the ACE approach. A backpropagation algorithm with a three-layer network was utilized to model the investigated alloy's flow behavior in the present work. The input layer (strain and deformation strain rate and temperature), the output layer (flow stress), and the hidden layer were the three selected layers used here. The graph in Figure 8 schematically demonstrates the ANN architecture. The function of TrainLM with a Tan-sigmoid hidden-transfer function and a Purelin output-transfer function were utilized for the ANN training due to its speed and effectiveness [80,81].

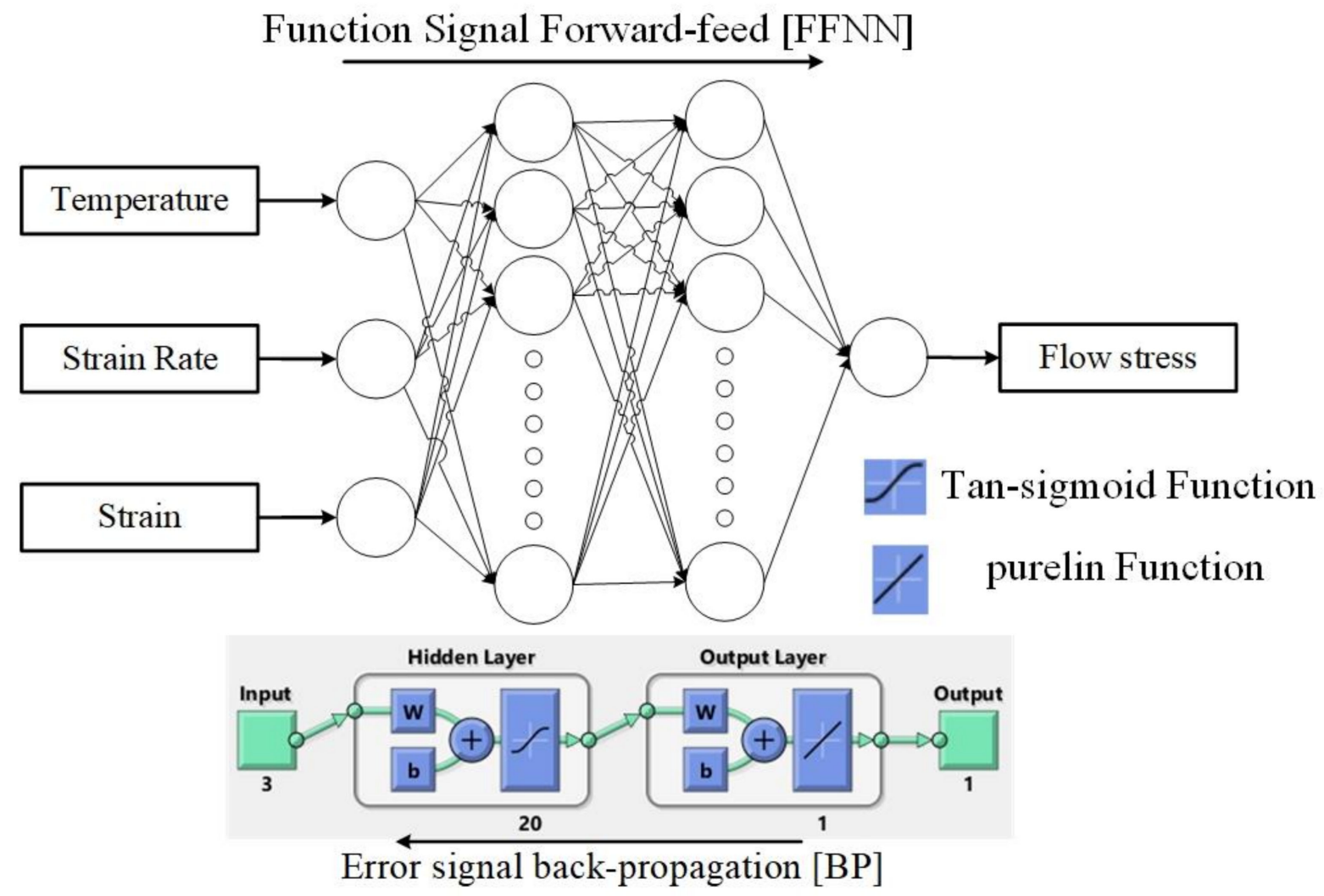

Figure 8. Artificial neural network (ANN) architecture schematic illustration for the used network.

With one neuron in the hidden layer, the trial-and-error process was initiated and further executed with more neurons. A suitable number of hidden layers should be 
identified. Figure 9 illustrates the reliance on the network efficiency of the number of neurons in the hidden layer. To verify the output of the used ANN, the mean squared error (MSE) was used. It was found that at 20 neurons, the MSE reached the minimum value. The relationship between the fitted stresses and the experimental stresses derived from the ANN model is shown in Figure 10. At the studied temperature and strain rate ranges, the fitted and approximated stresses were in excellent compliance with the experimental stresses.

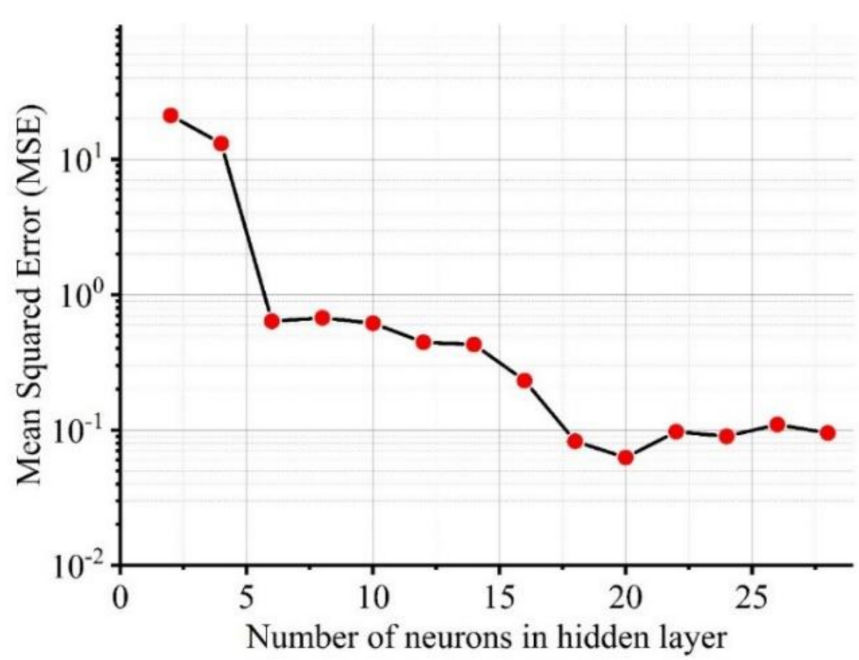

Figure 9. Dependence of the mean squared error (MSE) in the hidden layer vs. the number of neurons.
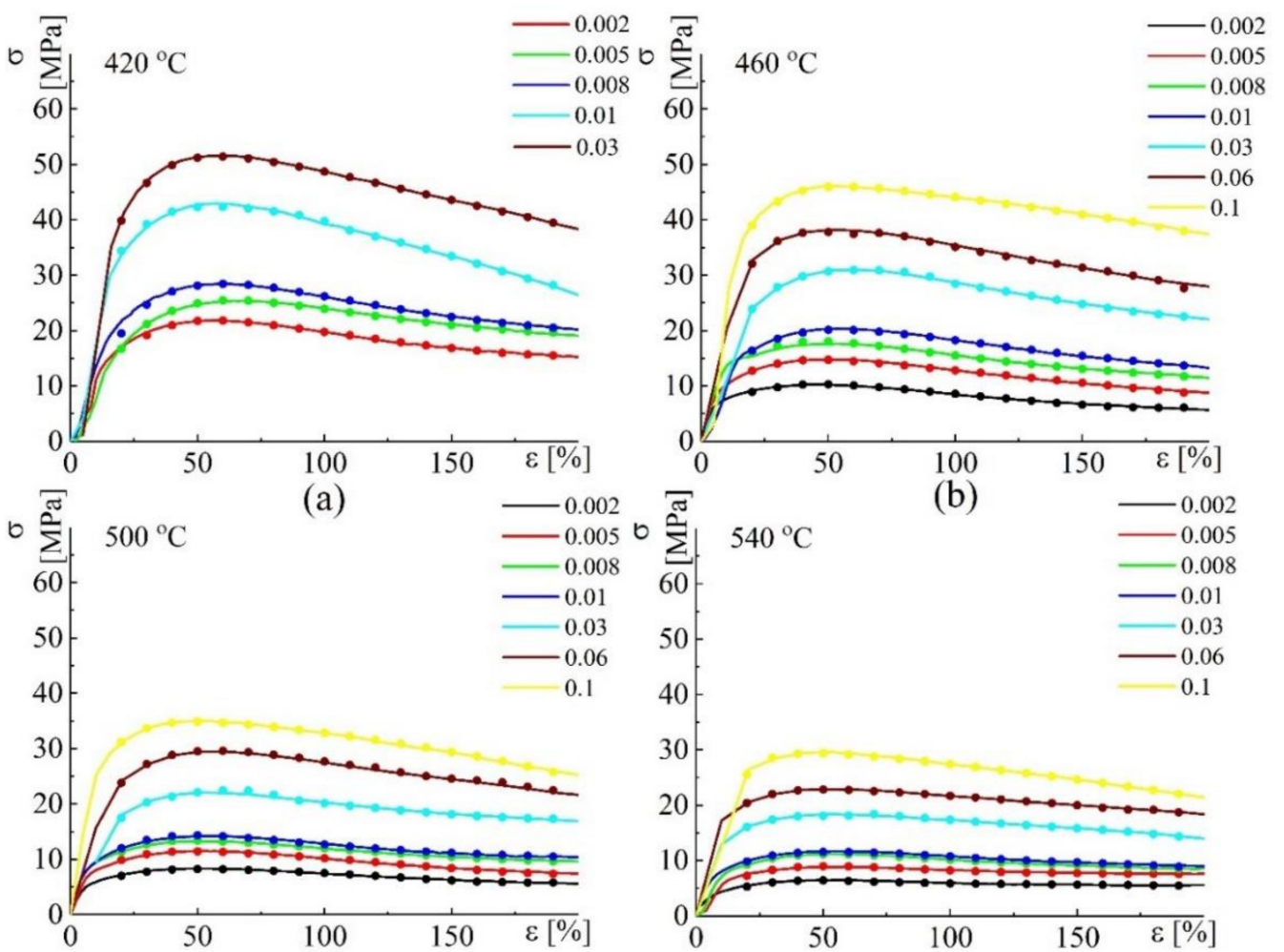

(c)

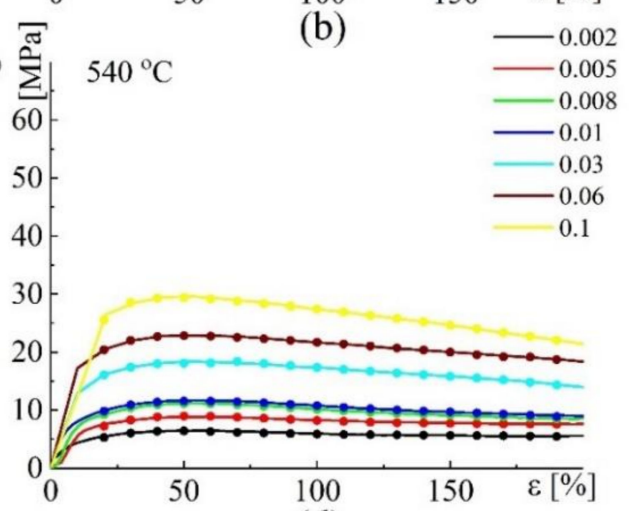

(d)

Figure 10. Experimental and predicted stress vs. strain via the ANN model at different strain rates and temperatures of (a) $420^{\circ} \mathrm{C}$, (b) $460{ }^{\circ} \mathrm{C}$, (c) $500{ }^{\circ} \mathrm{C}$, and (d) $540{ }^{\circ} \mathrm{C}$. 


\subsubsection{Verification of the Proposed Models}

The prediction quality of the proposed models was quantified by the correlation coefficient (R), the average absolute relative error (AARE), and the root means square error (RMSE). Figure 11 displays the correlation between the experimental and the modeled flow stress via both ACE (Figure 11a) and ANN (Figure 11b) models. The values of the performance metrics R, AARE (\%), and RMSE for both models are presented in Table 4. Both ACE and ANN models demonstrated strong workability for the fitting of the flow stress of the investigated alloy; however, the ANN exhibited smaller errors than the ACE.

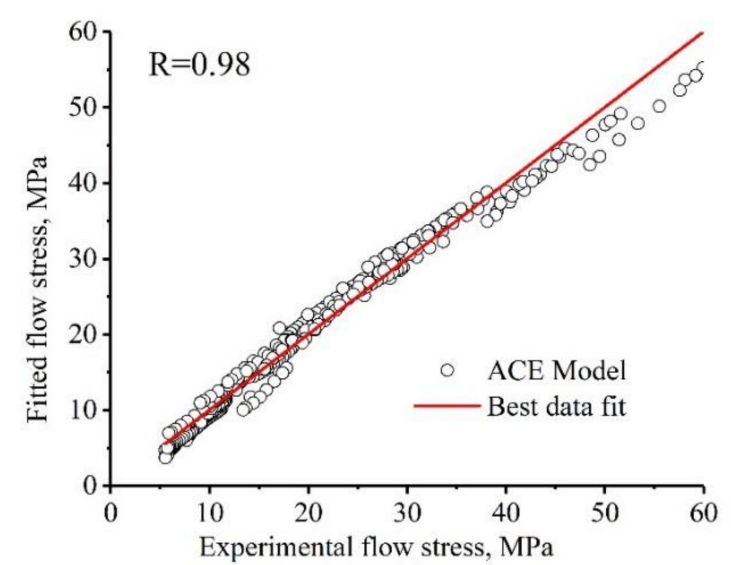

(a)

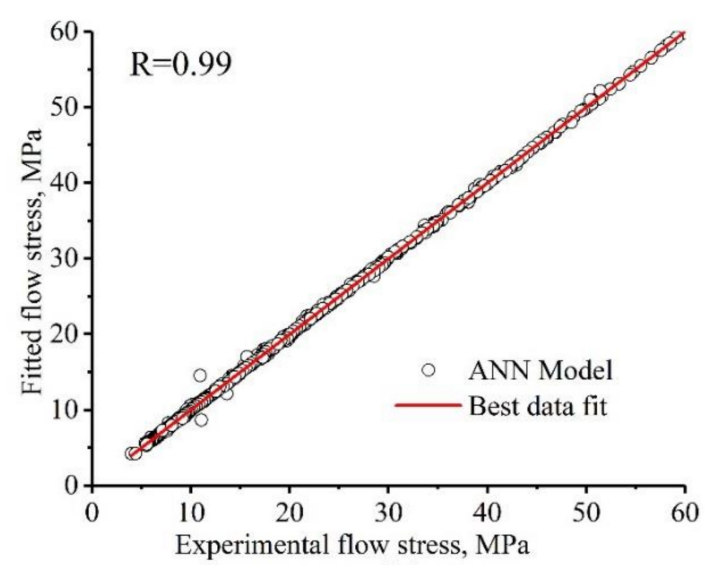

(b)

Figure 11. Correlation between the experimental and modeled flow stresses obtained by (a) ACE and (b) ANN models.

Table 4. Performance indicators the correlation coefficient (R), average absolute relative error (AARE) $(\%)$, and root means square error (RMSE) values of the proposed models after fitting and approximation of the flow behavior for the alloy studied.

\begin{tabular}{cccc}
\hline & $\mathbf{R}$ & RMSE & AARE (\%) \\
\hline ACE & 0.98 & 1.42 & $6.54 \%$ \\
\hline ANN & 0.99 & 0.27 & $0.91 \%$ \\
\hline
\end{tabular}

\subsubsection{Models Cross-validation}

The cross-validation method was used to compare the predictability of the proposed model, ACE and ANN. Both models were evaluated by extracting the stress-strain experimental curves tested at $500{ }^{\circ} \mathrm{C}$, and then the models were reconstructed without the data for $500{ }^{\circ} \mathrm{C}$. The prediction of the data tested at $500{ }^{\circ} \mathrm{C}$ was made. In the same manner, the prediction of the data tested at $1 \times 10^{-2} \mathrm{~s}^{-1}$ was performed. The comparison between the predicted by both ACE and ANN modelled and the experimental curves are shown in Figure 12. The predicted data by both models at $500^{\circ} \mathrm{C}$ (Figure $12 \mathrm{a}, \mathrm{c}$ ) and $1 \times 10^{-2} \mathrm{~s}^{-1}$ (Figure 12b,d) were in good agreement with the experimental data. 


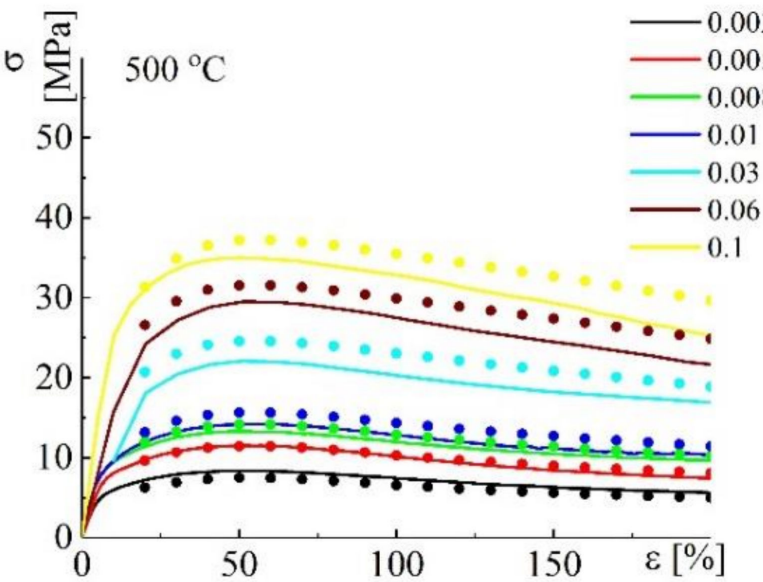

(a)

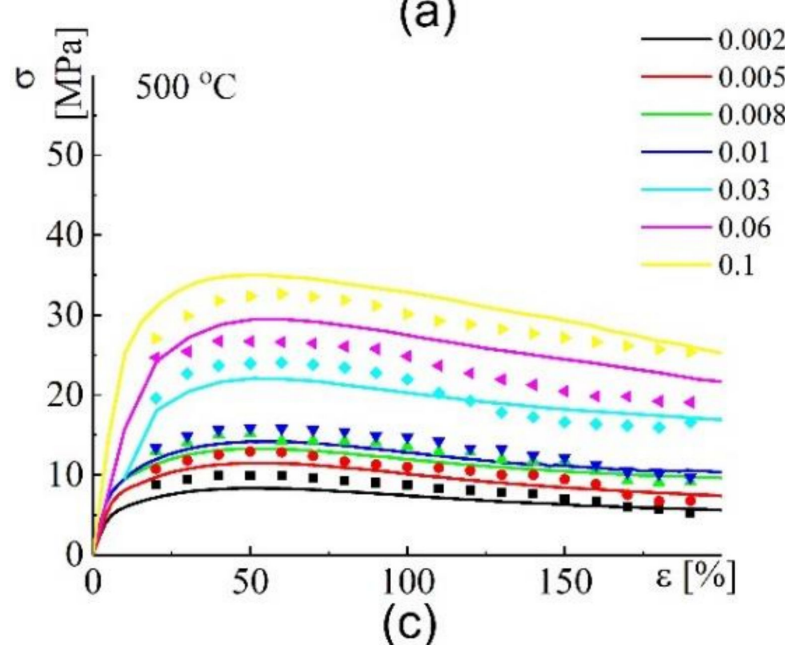

(c)

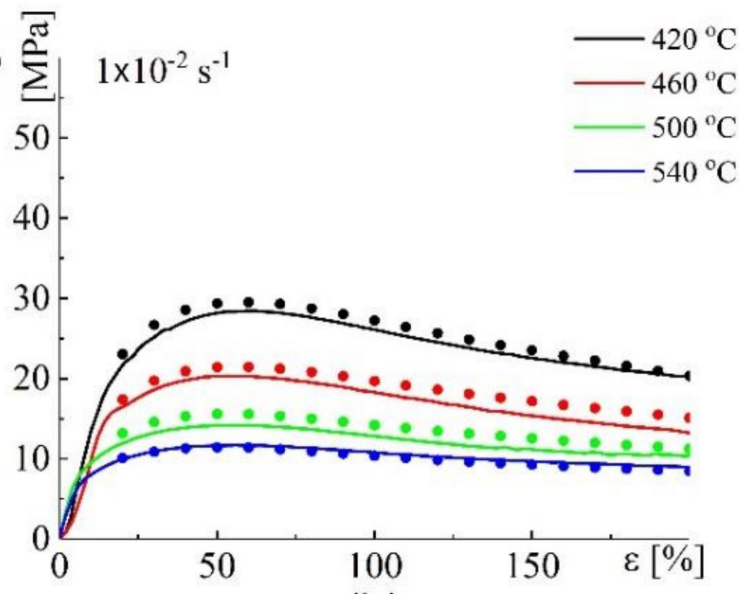

(b)

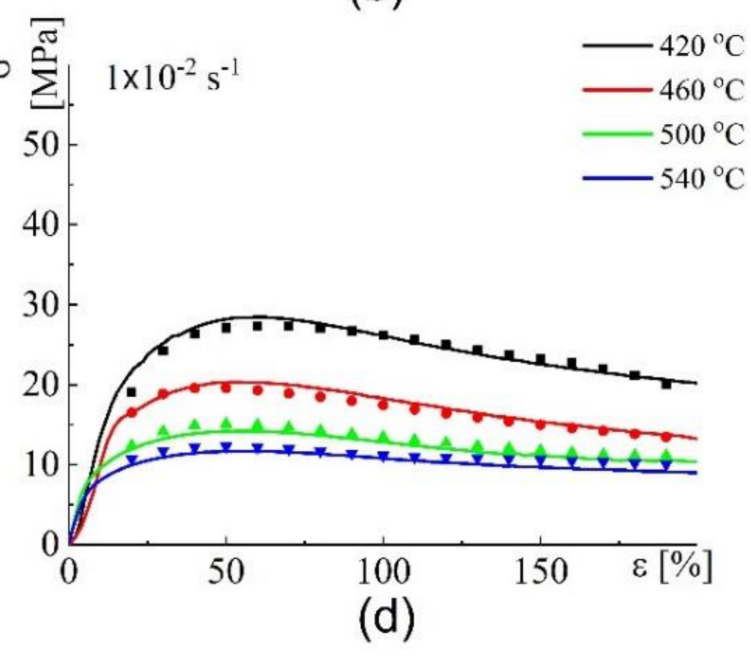

Figure 12. Compression between the experimental and predicted data by (a,b) ACE and (c,d) ANN at $(\mathbf{a}, \mathbf{c}) 500{ }^{\circ} \mathrm{C}$ and $(\mathbf{b}, \mathbf{d})$ $1 \times 10^{-2} \mathrm{~s}^{-1}$.

The prediction quality for the proposed models after cross-validation was quantified by R, AARE, and RMSE (Table 5). Figure 13 demonstrates the overall correlation between the experimental and the predicted flow stress via the ACE (Figure 13a,b) and ANN (Figure 13c,d) models at $500{ }^{\circ} \mathrm{C}$ and $0.01 \mathrm{~s}^{-1}$.

Table 5. Performance indicators R, AARE (\%), and RMSE values of the proposed models after prediction of the flow behavior of the investigated alloy via a cross-validation technique.

\begin{tabular}{ccccccc}
\hline & \multicolumn{2}{c}{$\mathbf{R}$} & \multicolumn{2}{c}{$\mathbf{R M S E}$} & \multicolumn{2}{c}{ AARE (\%) } \\
\cline { 2 - 7 } & $\mathbf{5 0 0}{ }^{\circ} \mathbf{C}$ & $\begin{array}{c}\mathbf{1} \times \mathbf{1 0}^{-\mathbf{2}} \\
\mathbf{s}^{-\mathbf{1}}\end{array}$ & $\mathbf{5 0 0}{ }^{\circ} \mathbf{C}$ & $\begin{array}{c}\mathbf{1} \times \mathbf{1 0}^{-\mathbf{2}} \\
\mathbf{s}^{-\mathbf{1}}\end{array}$ & $\mathbf{5 0 0}{ }^{\circ} \mathbf{C}$ & $\begin{array}{c}\mathbf{1} \times \mathbf{1 0}^{-\mathbf{2}} \\
\mathbf{s}^{-\mathbf{1}}\end{array}$ \\
\hline ACE & 0.98 & 0.98 & 1.92 & 1.2 & $9.5 \%$ & $7 \%$ \\
\hline ANN & 0.94 & 0.99 & 1.87 & 0.7 & $10.5 \%$ & $5 \%$ \\
\hline
\end{tabular}




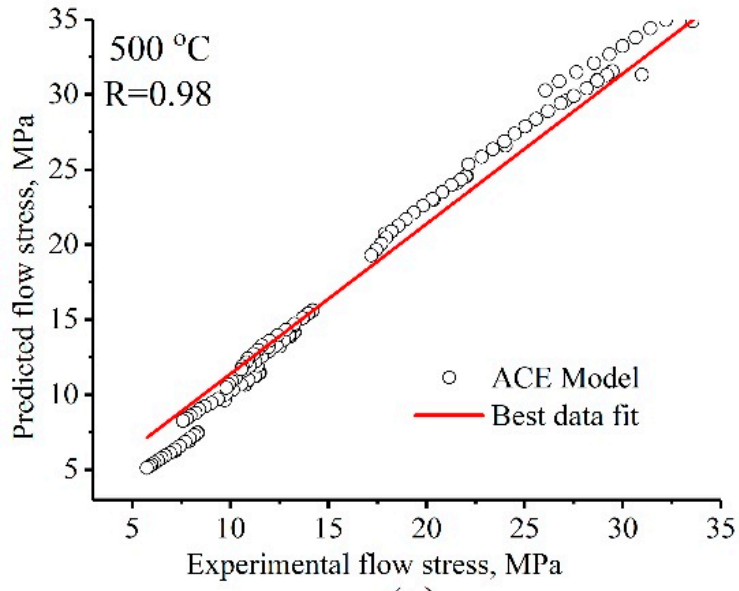

(a)

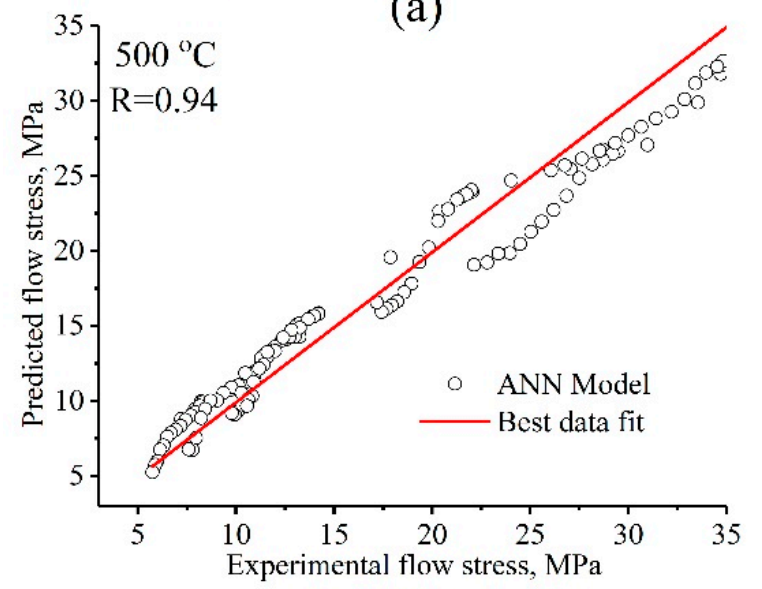

(c)

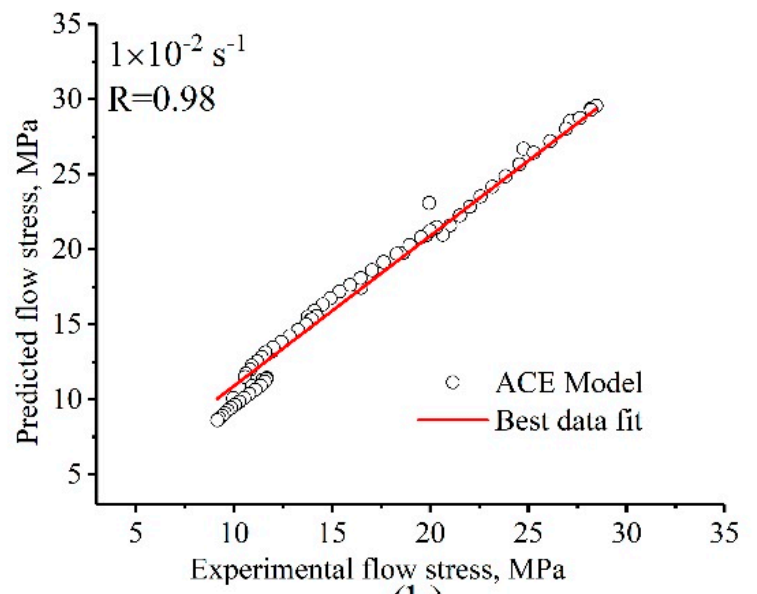

(b)

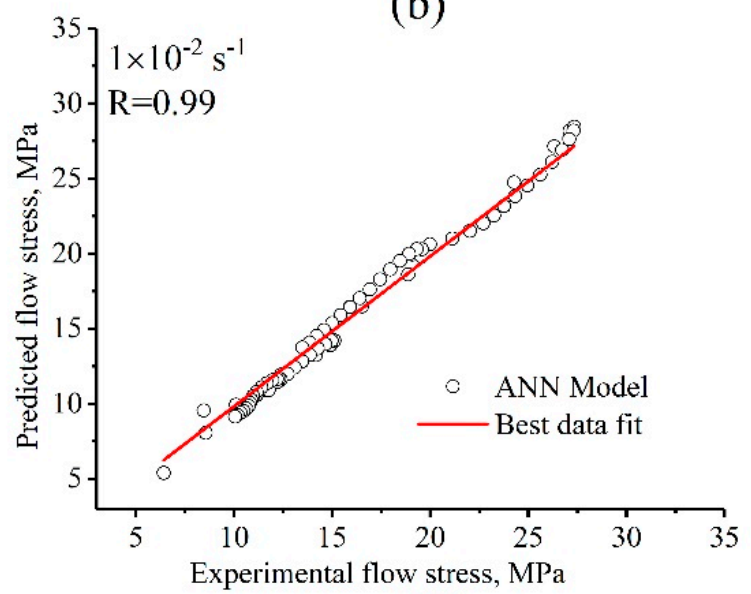

(d)

Figure 13. Correlation between the experimental and predicted flow stress obtained by (a,b) ACE and (c,d) ANN models.

Both ACE and ANN models demonstrated a good predictability of the flow stress behavior of the studied alloy. At $500{ }^{\circ} \mathrm{C}$, the minor difference between the modeled and experimental data were achieved for the strain rates in a range of $0.002-0.01 \mathrm{~s}^{-1}$ (Figure 14a,c). For higher strain rates, $0.03-0.1 \mathrm{~s}^{-1}$, the ACE model demonstrated a lower deviation from the experiments than that of the ANN model (Figure 14b,d). The proposed models are required for the simulation superplastic forming process and the prediction forming parameters. The models are important instruments for the optimization superplastic forming regimes and processed high-quality complex-shape parts from the alloy studied. 

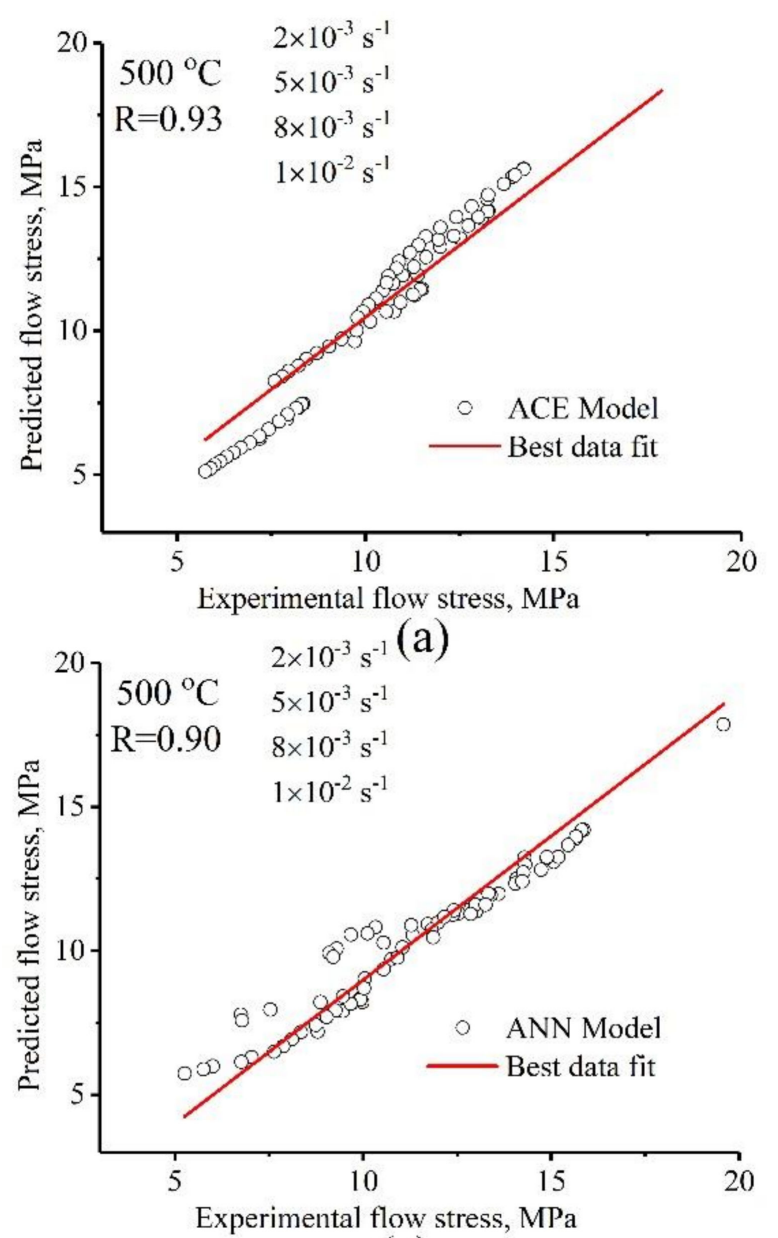

(c)

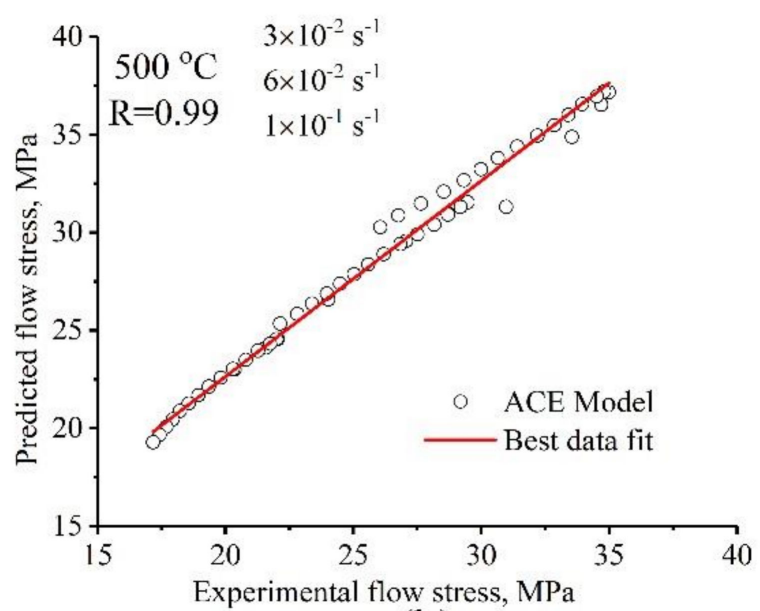

(b)

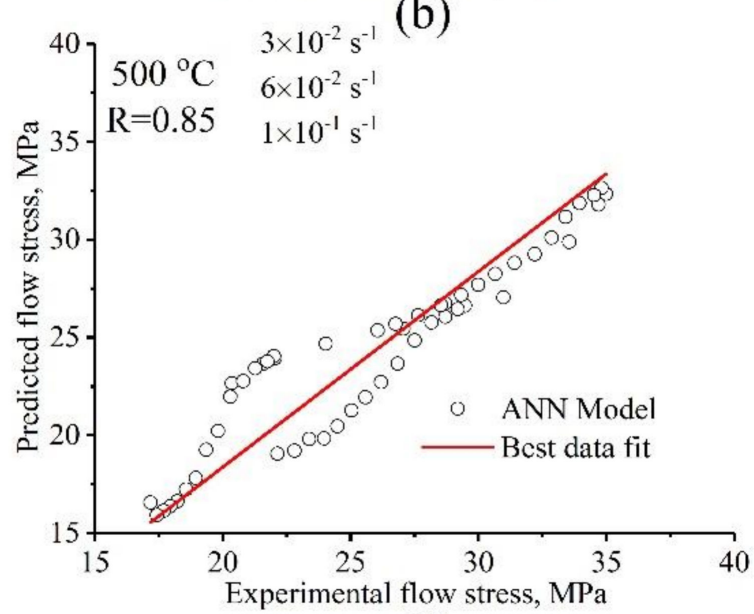

(d)

Figure 14. Correlation between the experimental and predicted flow stress obtained by $(\mathbf{a}, \mathbf{b})$ ACE and (c,d) ANN models at (a,c) $0.002-0.01 \mathrm{~s}^{-1}$ and $(\mathbf{b}, \mathbf{d}) 0.03-0.1 \mathrm{~s}^{-1}$.

\section{Conclusions}

The superplastic deformation behavior for the Al-Mg-Fe-Ni-Zr-Sc alloy in a temperature range of $420-540{ }^{\circ} \mathrm{C}$ and a strain-rate range of $0.002-0.1 \mathrm{~s}^{-1}$ was studied. The testing conditions provided the strain-rate-sensitivity $m$ coefficient of $0.35-0.55$ and elongation to failure of $250-570 \%$. Two mathematical models (Arrhenius type and artificial neural network) of the stress-strain behavior in superplastic conditions were developed. The following conclusions were drawn:

A The alloy studied containing coarse $\mathrm{Al}_{9} \mathrm{FeNi}$ particles of crystallization origin and fine $\mathrm{L}_{2}$-structured $\mathrm{Al}_{3} \mathrm{Zr}$ dispersoids exhibited a non-recrystallized grain structure before the start of the superplastic deformation. Due to dynamic recrystallization, a finegrained structure was formed during deformation, which provided high-strain-rate superplasticity with elongation-to-failure above $500 \%$. A higher strain rate provided a finer grain size for the alloy.

B The effective activation energy of the superplastic deformation suggested that the alloy deformation was controlled by the grain boundary self-diffusion of aluminum. The strain-rate-sensitivity coefficient $m$ values suggested that the grain boundary sliding mechanism was predominant and its contribution increased with increasing strain in the studied strain range.

C The Arrhenius-based model and the three-layer artificial neural network were developed. The hidden layer of the used artificial neural network contained 20 neutrons that exhibited a minimum error level. In fitting and approximating the hot deforma- 
tion behavior of the investigated alloy, the two constructed models demonstrated good performance. For the unmodeled deformation conditions, the cross-validation approach verified good predictability of the established models. However, relative to the artificial neural network model, the Arrhenius-based model demonstrated better predictability with a lower error level.

Author Contributions: Conceptualization, A.V.M.; methodology, A.A.K. and A.D.K.; investigation, A.A.K. and O.V.R.; modeling experiments, A.O.M.; writing—original draft preparation, A.O.M.; writing-review and editing, A.V.M.; supervision, A.V.M. All authors have read and agreed to the published version of the manuscript.

Funding: This research was funded by Russian Science Foundation, RF [Grant Number 17-79-20426].

Institutional Review Board Statement: Not applicable.

Informed Consent Statement: Not applicable.

Data Availability Statement: The raw and processed data required to reproduce these results are available by contacting the authors.

Acknowledgments: The study was funded by Russian Science Foundation, RF [Grant Number 17-79-20426]. The authors gratefully acknowledge E.M. Bazanova for her helpful recommendations.

Conflicts of Interest: The authors declare no conflict of interest.

\section{References}

1. Zhang, W.; Gao, Y.; Feng, Z.; Wang, X.; Zhang, S.; Huang, L.; Huang, Z.; Jiang, L. Ductility limit diagrams for superplasticity and forging of high temperature polycrystalline materials. Acta Mater. 2020, 194, 378-386. [CrossRef]

2. Williams, J.C.; Boyer, R.R. Opportunities and issues in the application of titanium alloys for aerospace components. Metals 2020, 10, 705. [CrossRef]

3. Aksenov, S.; Sorgente, D. Determination of biaxial stress-strain curves for superplastic materials by means of bulge forming tests at constant stress. CIRP J. Manuf. Sci. Technol. 2020, 31, 618-627. [CrossRef]

4. Aksenov, S.; Mikolaenko, V. The effect of material properties on the accuracy of superplastic tensile test. Metals 2020, 10, 1353. [CrossRef]

5. Jarrar, F.; Sorgente, D.; Aksenov, S.A.; Enikeev, F. On the Challenges and Prospects of the Superplastic Forming Process. Mater. Sci. Forum 2019, 941, 2343-2348. [CrossRef]

6. Grimes, R. 11-Superplastic forming of aluminium alloys. In Superplastic Forming of Advanced Metallic Materials; Woodhead Publishing Series in Metals and Surface Engineering; Giuliano, G., Ed.; Woodhead Publishing: Cambridge, UK, 2011; pp. 247-271. ISBN 9781845697532. Available online: https:/ / www.sciencedirect.com/science/article/pii/B978184569753250011X (accessed on 6 July 2020). [CrossRef]

7. XING, H.; Wang, C.; Zhang, K.; Wang, Z. Recent development in the mechanics of superplasticity and its applications. J. Mater. Process. Technol. 2004, 151, 196-202. [CrossRef]

8. Hirsch, J. Aluminium in innovative light-weight car design. Mater. Trans. 2011, 52, 818-824. [CrossRef]

9. Fereshteh-Saniee, F.; Fakhar, N.; Mahmudi, R. Influence of Combined Severe Plastic Deformation and Sheet Extrusion Process on the Superplastic Formability of AA 5083 Aluminum Alloy Assessed by Free Bulge Test. J. Mater. Eng. Perform. 2019, 28, 6682-6691. [CrossRef]

10. Dunwoody, B.J. The Production of Automotive Body Panels in 5083 SPF Aluminium Alloy. Mater. Sci. Forum 2001, 357-359, 59-64. [CrossRef]

11. Hefti, L.D. Commercial Airplane Applications of Superplastically Formed AA5083 Aluminum Sheet. J. Mater. Eng. Perform. 2007, 16, 136-141. [CrossRef]

12. Wang, X.G.; Li, Q.S.; Wu, R.R.; Zhang, X.Y.; Ma, L. A Review on Superplastic Formation Behavior of Al Alloys. Adv. Mater. Sci. Eng. 2018, 2018. [CrossRef]

13. Sorgente, D.; Tricarico, L. Characterization of a superplastic aluminium alloy ALNOVI-U through free inflation tests and inverse analysis. Int. J. Mater. Form. 2014, 7, 179-187. [CrossRef]

14. Kudo, T.; Goto, A.; Saito, K. High Strain Rate Blow Formability of Newly Developed Al-Mg-High-Mn Alloy. Mater. Sci. Forum 2013, 735, 271-277. [CrossRef]

15. Cleveland, R.M.; Ghosh, A.K.; Bradley, J.R. Comparison of superplastic behavior in two 5083 aluminum alloys. Mater. Sci. Eng. A 2003, 351, 228-236. [CrossRef]

16. Kishchik, A.A.; Mikhaylovskaya, A.V.; Kotov, A.D.; Rofman, O.V.; Portnoy, V.K. Al-Mg-Fe-Ni based alloy for high strain rate superplastic forming. Mater. Sci. Eng. A 2018, 718, 190-197. [CrossRef] 
17. Yakovtseva, O.A.; Sitkina, M.N.; Kotov, A.D.; Rofman, O.V.; Mikhaylovskaya, A.V. Experimental study of the superplastic deformation mechanisms of high-strength aluminum-based alloy. Mater. Sci. Eng. A 2020, 788, 139639. [CrossRef]

18. Bian, Z.; Liu, Y.; Dai, S.; Chen, Z.; Wang, M.; Chen, D.; Wang, H. Regulating microstructures and mechanical properties of Al-Fe-Ni alloys. Prog. Nat. Sci. Mater. Int. 2020, 30, 54-62. [CrossRef]

19. Shirinkina, I.G.; Brodova, I.G. Annealing-Induced Structural-Phase Transformations in an Al-Zn-Mg-Fe-Ni Alloy after High Pressure Torsion. Phys. Met. Metallogr. 2020, 121, 344-351. [CrossRef]

20. Belov, N.A. Sparingly alloyed high-strength aluminum alloys: Principles of optimization of phase composition. Met. Sci. Heat Treat. 2012, 53, 420-427. [CrossRef]

21. Yakovtseva, O.A.; Kotov, A.D.; Sitkina, M.N.; Irzhak, A.V.; Mikhaylovskaya, A.V. Mechanisms of Superplastic High-Rate Deformation in the Al-Mg-Zn-Fe-Ni-Zr-Sc Alloy. Phys. Met. Metallogr. 2019, 120, 1014-1020. [CrossRef]

22. Kotov, A.D.; Mikhaylovskaya, A.V.; Borisov, A.A.; Yakovtseva, O.A.; Portnoy, V.K. High-strain-rate superplasticity of the Al-Zn-Mg-Cu alloys with Fe and Ni additions. Phys. Met. Metallogr. 2017, 118, 913-921. [CrossRef]

23. Mikhaylovskaya, A.V.; Yakovtseva, O.A.; Cheverikin, V.V.; Kotov, A.D.; Portnoy, V.K. Superplastic behaviour of Al-Mg-Zn-Zr-Scbased alloys at high strain rates. Mater. Sci. Eng. A 2016, 659, 225-233. [CrossRef]

24. Mikhaylovskaya, A.V.; Kishchik, A.A.; Kotov, A.D.; Rofman, O.V.; Tabachkova, N.Y. Precipitation behavior and high strain rate superplasticity in a novel fine-grained aluminum based alloy. Mater. Sci. Eng. A 2019, 760, 37-46. [CrossRef]

25. Churyumov, A.Y.; Mikhaylovskaya, A.V.; Bazlov, A.I.; Tsarkov, A.A.; Kotov, A.D.; Aksenov, S.A. Influence of $\mathrm{Al}_{3} \mathrm{Ni}$ crystallisation origin particles on hot deformation behaviour of aluminium based alloys. Philos. Mag. 2017, 97, 572-590. [CrossRef]

26. Rollett, A.; Humphreys, F.; Rohrer, G.S.; Hatherly, M. Recrystallization and Related Annealing Phenomena: Second Edition, 1st ed.; Pergamon: London, UK, 2004; ISBN 9780080441641. [CrossRef]

27. Nes, E.; Wert, J.A. Modeling of recrystallization in alloys with a bimodal particle size distribution. Scr. Metall. 1984, 18, 1433-1438. [CrossRef]

28. Humphreys, F.J. The nucleation of recrystallization at second phase particles in deformed aluminium. Acta Metall. 1977, 25, 1323-1344. [CrossRef]

29. Bate, P.S.; Humphreys, F.J.; Ridley, N.; Zhang, B. Microstructure and texture evolution in the tension of superplastic Al-6Cu-0.4Zr. Acta Mater. 2005, 53, 3059-3069. [CrossRef]

30. Bate, P. The effect of deformation on grain growth in Zener pinned systems. Acta Mater. 2001, 49, 1453-1461. [CrossRef]

31. Deng, Y.; Zhang, G.; Yang, Z.; Xu, G. Microstructure characteristics and mechanical properties of new aerospace Al-Mg-Mn alloys with $\mathrm{Al}_{3}(\mathrm{Sc1}-\mathrm{xZrx})$ or $\mathrm{Al}_{3}(\mathrm{Er1}-\mathrm{xZrx})$ nanoparticles. Mater. Charact. 2019, 153, 79-91. [CrossRef]

32. Miyake, Y.; Sato, Y.; Teranishi, R.; Kaneko, K. Effect of heat treatments on the microstructure and formability of Al-Mg-Mn-Sc-Zr alloy. Micron 2017, 101, 151-155. [CrossRef] [PubMed]

33. Maeng, D.Y.; Lee, J.H.; Hong, S.I. The effect of transition elements on the superplastic behavior of Al-Mg alloys. Mater. Sci. Eng. A 2003, 357, 188-195. [CrossRef]

34. PENG, Y.; YIN, Z.; NIE, B.; ZHONG, L. Effect of minor Sc and Zr on superplasticity of Al-Mg-Mn alloys. Trans. Nonferrous Met. Soc. China 2007, 17, 744-750. [CrossRef]

35. Chuvil'deev, V.N.; Shadrina, I.S.; Nokhrin, A.V.; Kopylov, V.I.; Bobrov, A.A.; Gryaznov, M.Y.; Shotin, S.V.; Tabachkova, N.Y.; Chegurov, M.K.; Melekhin, N.V. An investigation of thermal stability of structure and mechanical properties of Al-0.5Mg-Sc ultrafine-grained aluminum alloys. J. Alloys Compd. 2020, 831, 154805. [CrossRef]

36. Sitdikov, O.; Garipova, R.; Avtokratova, E.; Mukhametdinova, O.; Markushev, M. Effect of temperature of isothermal multidirectional forging on microstructure development in the Al-Mg alloy with nano-size aluminides of Sc and Zr. J. Alloys Compd. 2018, 746, 520-531. [CrossRef]

37. Sitdikov, O.S.; Avtokratova, E.V.; Mukhametdinova, O.E.; Garipova, R.N.; Markushev, M.V. Effect of the Size of $\mathrm{Al}_{3}(\mathrm{Sc}, \mathrm{Zr})$ Precipitates on the Structure of Multi-Directionally Isothermally Forged Al-Mg-Sc-Zr Alloy. Phys. Met. Metallogr. 2017, 118, 1215-1224. [CrossRef]

38. Michi, R.A.; Toinin, J.P.; Seidman, D.N.; Dunand, D.C. Ambient- and elevated-temperature strengthening by $\mathrm{Al}_{3} \mathrm{Zr}-$ Nanoprecipitates and $\mathrm{Al}_{3} \mathrm{Ni}-\mathrm{Microfibers}$ in a cast Al-2.9Ni-0.11Zr-0.02Si-0.005Er (at.\%) alloy. Mater. Sci. Eng. A 2019, 759, 78-89. [CrossRef]

39. Mochugovskiy, A.G.; Mikhaylovskaya, A.V.; Zadorognyy, M.Y.; Golovin, I.S. Effect of heat treatment on the grain size control, superplasticity, internal friction, and mechanical properties of zirconium-bearing aluminum-based alloy. J. Alloys Compd. 2021, 856, 157455. [CrossRef]

40. Nokhrin, A.; Shadrina, I.; Chuvil'deev, V.; Kopylov, V. Study of Structure and Mechanical Properties of Fine-Grained Aluminum Alloys Al-0.6wt.\%Mg-Zr-Sc with Ratio Zr:Sc = 1.5 Obtained by Cold Drawing. Materials 2019, 12, 316. [CrossRef]

41. Ma, Z.Y.; Mishra, R.S.; Mahoney, M.W.; Grimes, R. High strain rate superplasticity in friction stir processed Al-Mg-Zr alloy. Mater. Sci. Eng. A 2003, 351, 148-153. [CrossRef]

42. Mochugovskiy, A.G.; Mikhaylovskaya, A.V.; Tabachkova, N.Y.; Portnoy, V.K. The mechanism of L12 phase precipitation, microstructure and tensile properties of Al-Mg-Er-Zr alloy. Mater. Sci. Eng. A 2019, 744, 195-205. [CrossRef]

43. Kishchik, A.A.; Kotov, A.D.; Mikhaylovskaya, A.V. The Microstructure and High-Strain-Rate Superplasticity of the Al-Mg-Ni-FeMn-Cr-Zr Alloy. Phys. Met. Metallogr. 2019, 120, 1006-1013. [CrossRef] 
44. Zang, Q.; Yu, H.; Lee, Y.S.; Kim, M.S.; Kim, H.W. Hot deformation behavior and microstructure evolution of annealed Al-7.9Zn2.7Mg-2.0Cu (wt\%) alloy. J. Alloys Compd. 2018, 763, 25-33. [CrossRef]

45. Ren, X.; Jia, L.; Zhang, K. Stress-strain relation during superplastic uniaxial tension at constant tension velocity. Eng. Res. Express 2019, 1, 015035. [CrossRef]

46. Shen, J.; Hu, L.; Sun, Y.; Wan, Z.; Feng, X.; Ning, Y. A Comparative Study on Artificial Neural Network, Phenomenological-Based Constitutive and Modified Fields-Backofen Models to Predict Flow Stress in Ti-4Al-3V-2Mo-2Fe Alloy. J. Mater. Eng. Perform. 2019, 28, 4302-4315. [CrossRef]

47. REZAEI ASHTIANI, H.R.; SHAHSAVARI, P. Constitutive modeling of flow behavior of precipitation-hardened AA7022-T6 aluminum alloy at elevated temperature. Trans. Nonferrous Met. Soc. China Engl. Ed. 2020, 30, 2927-2940. [CrossRef]

48. Chen, L.; Zhao, G.; Yu, J.; Zhang, W. Constitutive analysis of homogenized 7005 aluminum alloy at evaluated temperature for extrusion process. Mater. Des. 2015, 66, 129-136. [CrossRef]

49. Dong, Y.; Zhang, C.; Zhao, G.; Guan, Y.; Gao, A.; Sun, W. Constitutive equation and processing maps of an Al-Mg-Si aluminum alloy: Determination and application in simulating extrusion process of complex profiles. Mater. Des. 2016, 92, 983-997. [CrossRef]

50. Wang, Y.; Zhao, G.; Xu, X.; Chen, X.; Zhang, C. Constitutive modeling, processing map establishment and microstructure analysis of spray deposited Al-Cu-Li alloy 2195. J. Alloys Compd. 2019, 779, 735-751. [CrossRef]

51. Feng, D.; Zhang, X.M.; Liu, S.D.; Deng, Y.L. Constitutive equation and hot deformation behavior of homogenized Al-7.68Zn2.12Mg-1.98Cu-0.12Zr alloy during compression at elevated temperature. Mater. Sci. Eng. A 2014, 608, 63-72. [CrossRef]

52. Rasaee, S.; Mirzaei, A.H.; Almasi, D. Constitutive modelling of Al7075 using the Johnson-Cook model. Bull. Mater. Sci. 2020, 43, 1-8. [CrossRef]

53. Mimaroglu, A.; Yenihayat, O.F. Modelling the superplastic deformation process of 2024 aluminium alloys under constant strain rate: Use of finite element technique. Mater. Des. 2003, 24, 189-195. [CrossRef]

54. Cao, F.R.; Zhou, B.J.; Bin, Y.I.N.; Xue, G.Q.; Zhu, X.T.; Xu, G.M. Modeling of deformation energy at elevated temperatures and its application in Mg-Li-Al-Y alloy. Trans. Nonferrous Met. Soc. China Engl. Ed. 2017, 27, 2434-2442. [CrossRef]

55. Yakovtseva, O.; Sitkina, M.; Mosleh, A.O.; Mikhaylovskaya, A. High strain rate superplasticity in Al-Zn-Mg-based alloy: Microstructural design, deformation behavior, and modeling. Materials 2020, 13, 2098. [CrossRef]

56. Li, J.; Li, F.; Cai, J.; Wang, R.; Yuan, Z.; Xue, F. Flow behavior modeling of the 7050 aluminum alloy at elevated temperatures considering the compensation of strain. Mater. Des. 2012, 42, 369-377. [CrossRef]

57. Mondolfo, L.F. Aluminum Alloys Structure and Properties; Elsevier Ltd.: Amsterdam, The Netherlands, 1976; ISBN 978-0-408-70932-3.

58. Belov, N.A.; Eskin, D.G.; Aksenov, A.A. Multicomponent Phase Diagrams, Chapter 7-Alloys with Nickel; Elsevier: Amsterdam, The Netherlands, 2005; pp. 223-256. ISBN 9780080445373. Available online: https://www.sciencedirect.com/science/article/pii/B9 78008044537350007X (accessed on 6 July 2020). [CrossRef]

59. Mochugovskiy, A.G.; Mikhaylovskaya, A.V. Comparison of precipitation kinetics and mechanical properties in Zr and Sc-bearing aluminum-based alloys. Mater. Lett. 2020, 275, 128096. [CrossRef]

60. Fuller, C.B.; Murray, J.L.; Seidman, D.N. Temporal evolution of the nanostructure of Al(Sc,Zr) alloys: Part i-Chemical compositions of $\mathrm{Al}_{3}(\mathrm{Sc1}-\mathrm{xZrx})$ precipitates. Acta Mater. 2005, 53, 5401-5413. [CrossRef]

61. Belov, N.A.; Alabin, A.N.; Eskin, D.G.; Istomin-Kastrovskii, V.V. Optimization of hardening of Al-Zr-Sc cast alloys. J. Mater. Sci. 2006, 41, 5890-5899. [CrossRef]

62. Barkov, R.Y.; Mikhaylovskaya, A.V.; Yakovtseva, O.A.; Loginova, I.S.; Prosviryakov, A.S.; Pozdniakov, A.V. Effects of thermomechanical treatment on the microstructure, precipitation strengthening, internal friction, and thermal stability of $\mathrm{Al}-\mathrm{Er}-\mathrm{Yb}-\mathrm{Sc}$ alloys with good electrical conductivity. J. Alloys Compd. 2021, 855, 157367. [CrossRef]

63. Lefebvre, W.; Danoix, F.; Hallem, H.; Forbord, B.; Bostel, A.; Marthinsen, K. Precipitation kinetic of $\mathrm{Al}_{3}(\mathrm{Sc}, \mathrm{Zr})$ dispersoids in aluminium. J. Alloys Compd. 2009, 470, 107-110. [CrossRef]

64. Nieh, T.G.; Wadsworth, J.; Sherby, O.D. Superplasticity in Metals and Ceramics; Cambridge University Press: Cambridge, UK, 1997; ISBN 9780521561051.

65. Langdon, T.G. Seventy-five years of superplasticity: Historic developments and new opportunities. J. Mater. Sci. 2009, 44, 5998-6010. [CrossRef]

66. Bhatta, L.; Pesin, A.; Zhilyaev, A.P.; Tandon, P.; Kong, C.; Yu, H. Recent development of superplasticity in aluminum alloys: A review. Metals 2020, 10, 77. [CrossRef]

67. Sellars, C.M.; McTegart, W.J. On the mechanism of hot deformation. Acta Metall. 1966, 14, 1136-1138. [CrossRef]

68. Zener, C.; Hollomon, J.H. Effect of strain rate upon plastic flow of steel. J. Appl. Phys. 1944, 15, 22-32. [CrossRef]

69. Mosleh, A.O.; Mikhaylovskaya, A.V.; Kotov, A.D.; Portnoy, V.K. Arrhenius-Type Constitutive Equation Model of Superplastic Deformation Behaviour of Different Titanium Based Alloys. In Defect and Diffusion Forum; Trans Tech Publications Ltd.: Bäch, Switzerland, 2018.

70. Ruano, O.A.; Sherby, O.D. On constitutive equations for various diffusion-controlled creep mechanisms. Rev. Phys. Appliquée 1988, 23, 625-637. [CrossRef]

71. Kawasaki, M.; Balasubramanian, N.; Langdon, T.G. Flow mechanisms in ultrafine-grained metals with an emphasis on superplasticity. Mater. Sci. Eng. A 2011, 528, 6624-6629. [CrossRef] 
72. Mosleh, A.; Mikhaylovskaya, A.; Kotov, A.; Pourcelot, T.; Aksenov, S.; Kwame, J.; Portnoy, V. Modelling of the Superplastic Deformation of the Near- $\alpha$ Titanium Alloy (Ti-2.5Al-1.8Mn) Using Arrhenius-Type Constitutive Model and Artificial Neural Network. Metals 2017, 7, 568. [CrossRef]

73. Mikhaylovskaya, A.V.; Mosleh, A.O.; Kotov, A.D.; Kwame, J.S.; Pourcelot, T.; Golovin, I.S.; Portnoy, V.K. Superplastic deformation behaviour and microstructure evolution of near- $\alpha$ Ti-Al-Mn alloy. Mater. Sci. Eng. A 2017, 708, 469-477. [CrossRef]

74. Dai, Q.S.; Deng, Y.L.; Tang, J.G.; Wang, Y. Deformation characteristics and strain-compensated constitutive equation for AA5083 aluminum alloy under hot compression. Trans. Nonferrous Met. Soc. China Engl. Ed. 2019, 29, 2252-2261. [CrossRef]

75. Mirzadeh, H.; Roostaei, M.; Parsa, M.H.; Mahmudi, R. Rate controlling mechanisms during hot deformation of Mg-3Gd-1Zn magnesium alloy: Dislocation glide and climb, dynamic recrystallization, and mechanical twinning. Mater. Des. 2015, 68, 228-231. [CrossRef]

76. Kotov, A.D.; Mikhailovskaya, A.V.; Mosleh, A.O.; Pourcelot, T.P.; Prosviryakov, A.S.; Portnoi, V.K. Superplasticity of an UltrafineGrained Ti-4\% Al-1\% V-3\% Mo Alloy. Phys. Met. Metallogr. 2019, 120, 60-68. [CrossRef]

77. Kotov, A.D.; Mikhaylovskaya, A.V.; Kishchik, M.S.; Tsarkov, A.A.; Aksenov, S.A.; Portnoy, V.K. Superplasticity of high-strength Al-based alloys produced by thermomechanical treatment. J. Alloys Compd. 2016, 688, 336-344. [CrossRef]

78. Duan, Y.L.; Tang, L.; Deng, Y.; Cao, X.W.; Xu, G.F.; Yin, Z.M. Superplastic behavior and microstructure evolution of a new Al-Mg-Sc-Zr alloy subjected to a simple thermomechanical processing. Mater. Sci. Eng. A 2016, 669, 205-217. [CrossRef]

79. Kotov, A.D.; Mikhaylovskaya, A.V.; Portnoy, V.K. Effect of the solid-solution composition on the superplasticity characteristics of Al-Zn-Mg-Cu-Ni-Zr Alloys. Phys. Met. Metallogr. 2014, 115, 730-735. [CrossRef]

80. Yan, J.; Pan, Q.L.; Li, A.D.; Song, W.B. Flow behavior of Al-6.2Zn-0.70Mg-0.30Mn-0.17Zr alloy during hot compressive deformation based on Arrhenius and ANN models. Trans. Nonferrous Met. Soc. China Engl. Ed. 2017, 27, 638-647. [CrossRef]

81. Haghdadi, N.; Zarei-Hanzaki, A.; Khalesian, A.R.; Abedi, H.R. Artificial neural network modeling to predict the hot deformation behavior of an A356 aluminum alloy. Mater. Des. 2013, 49, 386-391. [CrossRef] 